\title{
The Structuralist Growth Model
}

\author{
Bill Gibson*
}

\begin{abstract}
This paper examines the underlying theory of structuralist growth models in an effort to compare that framework with the standard approach of Solow and others. Both the standard and structuralist models are solved in a common mathematical framework that emphasizes their similarities. It is seen that while the standard model requires the growth rate of the labor force to be taken as exogenously determined, the structuralist growth model must take investment growth to be determined exogenously in the long run. It is further seen that in order for the structuralist model to reliably converge to steady growth, considerable attention must be given to how agents make investment decisions. In many ways the standard model relies less on agency than does the structuralist. While the former requires a small number of plausible assumptions for steady growth to emerge, the structuralist model faces formidable challenges, especially if investment growth is thought to be determined by the rate of capacity utilization.
\end{abstract}

\section{Introduction}

The structuralist growth model (SGM) has its roots in the General Theory of Keynes (1936), Kalecki (1971) and efforts by Robinson (1956), Harrod (1937), Domar (1946), Pasinetti (1962) and others to extend the Keynesian principle of effective demand to the long run. The central concept of growth models in this tradition is the dual role played by investment, both as a component of aggregate demand and as a flow that augments the stock of capital. The basic structuralist model has been extended to cover a wide variety of topics, including foreign exchange constraints, human capital (Dutt, 2008, Gibson, 2005), the informal sector and macroeconomic policy analysis (Lima and Setterfield, 2008). The model has served as a foundation for large-scale computable general equilibrium models (Taylor, 1990), (Gibson and van Seventer, 2000).

This paper reviews the logic of the basic SGM and some of its variants and compares and contrasts the SGM with the standard growth models of Solow (1956) and developments thereafter (Barrow and Sala-iMartin, 2004). Both the structuralist and standard growth models are solved within a common mathematical framework and it is seen that each relies on an exogenously given rate of growth of a key variable. In the case of the standard model, it is the labor force and for the structuralists, it is the growth of effective demand. In both cases these variables are taken as given for good reason: they are notoriously difficult to model accurately. It is seen that when structuralists attempt to endogenize effective demand in a meaningful way, thorny problems arise and structuralists increasingly rely on models of agency rather than structure.

The paper is organized as follows. After some general observations on the nature of the SGM and its standard counterpart in the second section, the third discusses the basic mathematical framework of the two models and attention is drawn to the effort to endogenize investment growth via dependence on capacity utilization. The fourth section introduces the functional distribution of income and shows how it can solve the problems of instability generated by the attempt to endogenize investment. A concluding section offers some final thoughts on the project of comparing the two models.

*March 2009, Version 1.1, University of Vermont, Burlington, VT 05045; bill.gibson@uvm.edu. Thanks to Diane Flaherty and Mark Setterfield for invaluable comments in the preparation of this paper. 


\section{Perspectives on the SGM}

As the Keynesian model has fallen out of fashion in the profession as a whole, so too has interest in SGMs, per se, outside of a small community of authors. But this is not to say that the questions addressed by the structuralists are unimportant or passé. Modern endogenous growth models, for example, are highly structural in nature, if structure is defined as a shared context in which individual decisions about production and consumption are made (Aghion and Howitt, 1998; Zamparelli, 2008).

In challenging the orthodoxy of the time, early structuralists confronted the profession with a range of unanswered questions, from why there is still mass unemployment in many countries of the world to how financial crises emerge and propagate (Gibson, 2003a). Early structuralists proposed the anti-thesis to the accepted wisdom of the perfectly competitive general equilibrium model and the welfare propositions that logically flowed from it. It is not an exaggeration to say that much of the standard literature today that focuses on innovation and spillovers, strategic interaction, asymmetric information and the like, is a synthesis of the naive competitive model and its critique offered by Marxist, post-Keynesian and other heterodox challenges, including structuralists (Gibson, 2003b). To the extent that the early structuralists had a contribution to make, it was to identify contours of empirical reality that had been omitted in the rush to coherent reasoning about how an economy functions.

This is not to say that structuralists necessarily were or are content with the way that standard economic theory has appropriated their insights. The orthodoxy perhaps errs in its overemphasis of agency in the same way the early structuralist work seemed to deny it. But in venturing into the area of growth, structuralists risked a serious confrontation with their own view of how models were properly constructed. It is one thing to say that the level of effective demand is given in the short run, determined by a multiplier process on investment, which in turn depends on "animal spirits." But ultimately structure is nothing more than accumulated or fossilized agency. Taking animal spirits as a long-run explanation is therefore tantamount to saying that structure itself cannot be resolved theoretically. Some structuralists do seem to be comfortable with this implication, but this is hardly a satisfying position, and possibly the denouement of the structuralist approach. Recent efforts to incorporate hysteresis and remanence into structuralist models are necessarily drawn to more sophisticated models of microeconomic agent behavior. Good models of accumulation must have good models of agency at their core.

For the SGM, the process begins with the very definition of the independent investment function. Structuralists generally hold that investment should be modeled as co-dependent on a wholly exogenous animal spirits term and some endogenous motivational variable, usually capacity utilization or the rate (or share) of profit. The problem is that capacity utilization introduces dynamic instability into the model, as shall be seen in detail below, and some other economic process must be introduced to counteract the destabilizing force. Moreover, there is no guarantee that the rate of capacity utilization will converge to one (or any other specific number) in the long run. Whether from the labor market, the financial environment, the trade regime, fiscal and monetary policy or simply the mechanics of monopoly and competition, some force must come into play in order to arrest the tendency of the economy to self-destruct, increasing at an increasing rate or the opposite, until the structure disintegrates.

This implies that structuralists must think hard about factors other than structure when it comes to growth models. In the short run, agency is constrained by structure, but in the long run, agency must determine structure, simply because there is nothing else. As we shall see, there is a tendency to deny this basic fact among structuralist writers and it can lead to results that are wildly at variance with the data on how actual economies accumulate capital. Few structuralist models, for example, deal effectively with technical progress and diffusion and most deal with a representative firm and two social classes, eliminating the possibility of emergent properties from the interaction of agents at the micro level 1

\section{Dynamic models}

Lavoie (1992) notes that the key components in post-Keynesian and structuralist models are the roles of

\footnotetext{
${ }^{1}$ An important exception to this is Setterfield and Budd $(2008)$. See also Gibson $(2007)$.
} 
effective demand and time. The role of effective demand certainly distinguishes the SGM, but all dynamic models must treat time carefully. Indeed, the central concept of any dynamic economic model is the stockflow relationship. Economic models built on a mathematical chassis break up the flow of time into discrete units so that it is possible to talk about time "within the period" versus "between periods". Within periods variables jump into equilibrium, while variables that describe the state of the environment change between periods. Thus, models are thought to have enough time to get into a temporary equilibrium within a period. This implies that markets clear, by way of prices, quantities or some combination of the two, and that savings is equal to investment at the aggregate level. But within the period, the economy does not arrive at a fully adjusted equilibrium, since the forces that drive the state variables have not had time to do their work. Expectations of future events may influence behavior but there is no time for agents to determine if their expectations are indeed correct. While it is analytically simpler to think in terms of discrete time models, it is mathematically simpler to solve continuous time models. The latter come about as we shrink the discrete units of time and periods get too short to allow much to happen that is not contemporaneous. Adjustment between periods occurs at the same pace as adjustment within the period. While analytical models are usually, but not always, solved in continuous time, computer simulation of applied models must take place in discrete time.

Much of the discussion of macroeconomic models is about how the economy gets into short-run equilibrium. The "closure debate" of the last century focused on whether savings drives investment or vice-versa. In the standard model of dynamic economics, capacity utilization is always equal to one and so there is no role for effective demand. Factor availability determines output through a sequence of adjustment in goods and factor prices. In the structuralist view, price is a state variable and quantity adjustments, within the period, bring the economy to a temporary equilibrium. The principal role of the price variable is to determine the distribution of income. It is roughly correct to say, then, that in the standard model, the jump variables are prices, while in the structuralist model it is quantities. In the former model, factor quantities adjust between periods, while in the latter, prices, and thus income distribution, adjust between periods.

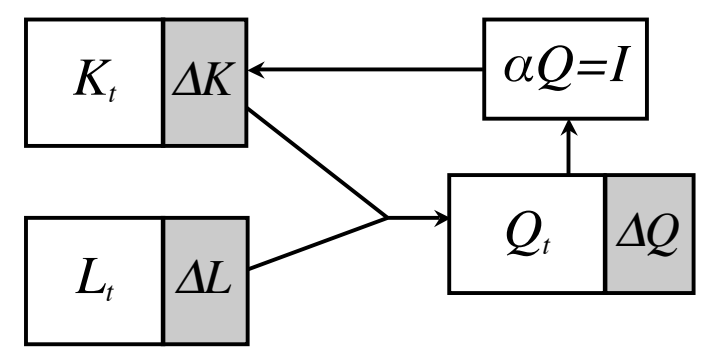

Figure 1: Accumulation of capital

Figure 1 is a schematic of a generic growth model in which output and investment growth are linked. Factors of production are combined to produce output, $Q$. Some fraction, $\alpha$, of the output is accumulated as capital, which increases the quantity of capital by $\Delta K$, after accounting for depreciation. This process take some time, during which the other factor of production, labor, also expands by $\Delta L$.

The standard model adheres to this schematic very closely. Once the factor inputs are known, the outputs are determined by way of a production function. Flexible prices ensure that all that can be produced from the factors of production is used for either consumption or investment. The fraction of output reinvested is not determined endogenously, but taken as a given parameter. This is also true of the growth rate of the labor force, $n$, as well as the underlying technology.

The SGM is, in many ways, more complex. As noted, there is an independent investment function that 
is not tied directly to output though a savings propensity. The links between the factors of production and output in figure 1 can be broken in the transient state. The arrows in the diagram are still present, but now represent constraints that may or may not have slack. If the capital constraint does not bind, then there is excess capacity and if there is slack in the labor constraint, there is unemployment. Either one or both can be present in structuralist models.

When neither of the constraints binds, the SGM takes on the configuration shown in figure 2. Investment is at the center of the model as it generates both demand and the change in the capital stock. The latter determines the capacity, $Q$, by way of a fixed capital-output ratio, $v 2^{2}$ Since capacity utilization, $u$, is the ratio of aggregate demand to capacity, investment directly or indirectly determines all the variables of the model.

Depending on the relative strength of investment to create demand or capacity, $u$ rises or falls in the transient state. The feed-back loop from $u$ that affects investment growth is shown by the dotted line in figure 2. When capacity utilization is high, investment accelerates to generate more capacity. But since the same investment also creates proportionately more demand, an explosive cycle can easily result. The solution, adopted by most structuralists, is to weaken the effect of capacity utilization on investment, in order to enhance the stability of the system. This sequence may well conflict with actual data: the paper by Skott in this volume points out a savings shock in the canonical Kaleckian model produces very large changes in utilization, but negative changes in utilization do not seem to be correlated with big savings shocks in U.S. data. The take-away point from figures 1 and 2 is that investment is the independent variable of the SGM,

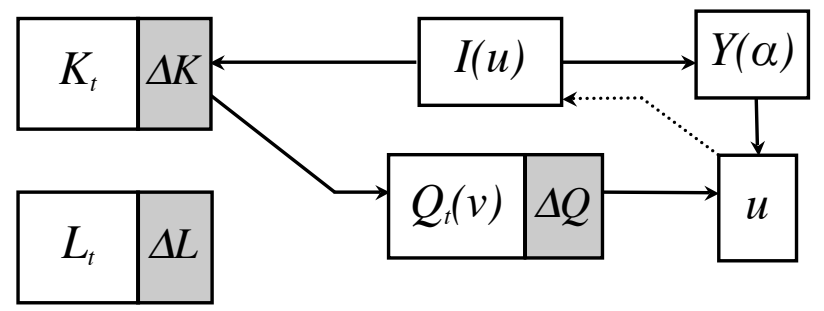

Figure 2: Structure of the investment constrained structuralist model

whereas it is derivative of factor growth in the standard model. Investment in the SGM may depend on $u$ recursively, but it certainly cannot be defined as a homogeneous function of capacity utilization. Something more must be given, usually referred to as "animal spirts." Most SGM investment functions rely on a (positive) constant to capture the effect of animal spirits and then repress the effect of capacity utilization on investment in the calibration of the model.

\subsection{Model calibration}

For applied discrete models it is approximately correct to think of each time period as described by a social accounting matrix (SAM). Dynamic linkages then join a sequence of SAMs. In the simplified SAM of table1. there is no government or foreign sector, only firms and households. GDP is then firm income, $Y$, the sum

\footnotetext{
${ }^{2}$ Most structuralists, post-Keynesian and Kaleckian writers ignore factor substitution or the choice of technique problem. There are exceptions, see for example Skott (1989). Mostly, however, the production function that governs the path of the capital-output ratio in the standard model is absent and without a production function, the default option is to assume a constant capital-output ratio. Unfortunately, this assumption that is flatly contradicted by the historical record; see Mohun (2008) and references cited therein.
} 
Table 1: A Social Accounting Matrix

\begin{tabular}{ccccc}
\hline & Firms & Household & Investment & Total \\
Firms & & $C$ & $I$ & $Y$ \\
HHolds & $V_{A}$ & & & $Y_{h}$ \\
profits & $\pi$ & & & $Y_{\pi}$ \\
wages & $\lambda$ & & & $Y_{\lambda}$ \\
Savings & & $S$ & & $S$ \\
Total & $Y$ & $Y_{h}$ & $I$ & \\
& & & & \\
\hline
\end{tabular}

of consumption and investment. Household income, $Y_{h}$, is value added, $V_{A}$, the sum of wage and profits, and total savings, $S$, is equal to total investment $I$.

The SAM provides a boundary condition, some point in the time trajectory through which the model must pass. Typically these are the initial conditions for the dynamic model. In principle, the SAM could describe any point along the trajectory, even a long-run steady state. It is impossible to tell if the economy of the SAM of table 1 is growing without knowing the composition of investment. The latter is is decomposed into replacement and net investment, $I_{n}$, defined as

$$
I_{n}=I-\delta K
$$

where replacement investment is $\delta K$. Here $\delta$ is the fraction of the capital stock lost to wear and tear or obsolescence during the period. If $I$ is less than replacement investment, the economy is contracting; if $I$ is equal to replacement investment, it is in the stationary state. In the latter case, investment just balances the charge for depreciation, $\delta K$, and so net investment is zero. If there is net investment, the economy of the SAM is expanding.

The SAM is constructed for time $t$ and the capital stock at the beginning of the period is $K_{t}$. The capital stock for the next period is given by the difference equation

$$
K_{t+1}=K_{t}(1-\delta)+I_{t}
$$

If the time-path of investment is known, this is a simple dynamical system in one variable, $K$. Define equilibrium in the path as the time period $t$ in which the change in the capital stock is zero. This will occur when

$$
\delta K_{t}=I_{t}
$$

This is the mathematical definition of the stationary state. To define steady-state growth, rewrite equation (2) as

$$
\hat{K}=\frac{I_{t}}{K_{t}}-\delta
$$

where the "hat" notation refers to growth rates ${ }^{3}$

Now it is evident from equation (4) that if $I_{t} / K_{t}$ were constant, so too would $\hat{K}$ be constant. Thus steady-state growth implies that

$$
\hat{I}=\hat{K}
$$

that is the rate of growth of investment must equal that of the capital stock ${ }^{4}$ Note, however, that equation (5) does not define any particular rate of growth for these two magnitudes. That depends on the level of

\footnotetext{
${ }^{3}$ That is, $\hat{K}$ is the growth rate of the capital stock, or $K_{t+1} / K_{t}-1$.

${ }^{4}$ The stationary state is then just a special case of the steady-state growth in which the growth rate is zero.
} 
$I / K$ at which the growth rates of the numerator and denominator come into equilibrium. This critical ratio can be re-expressed as

$$
\frac{I}{K}=\frac{I}{Q} \frac{Q}{K}=\frac{\alpha}{v}
$$

where $Q$ is output, $\alpha$ is the share of investment in output and $v$ is the capital-output ratio. If $v$ were known and it could be assumed that the economy were fully utilizing its capital stock, the steady-state growth rate could be determined by reading $\alpha$ directly from the SAM

Now let the growth rate of investment, $\hat{I}$, be known and denote it as $\gamma$. It is then possible to derive a continuous approximation to the time path of the economy that satisfies equation (4). Rewriting that equation

$$
\frac{d K}{d t}+\delta K=I_{0} e^{\gamma t}
$$

To solve this differential equation, an integrating factor of $e^{\int \delta d t}$ is introduced. Multiplying both sides

$$
\frac{d K}{d t} e^{\int \delta d t}+\delta K e^{\int \delta d t}=I_{0} e^{\gamma t} e^{\int \delta d t}
$$

where $e^{\int \delta d t}=e^{\delta t}$. So that

$$
K \delta e^{\delta t}+e^{\delta t} \frac{d K}{d t}=I_{0} e^{(\gamma+\delta) t}
$$

the left-hand side of which can be see as a derivative using the product rule

$$
\frac{d}{d t}\left(K e^{\delta t}\right)=I_{0} e^{(\gamma+\delta) t}
$$

This can be integrated by separation of variables to yield

$$
K e^{\delta t}=\frac{I_{0} e^{(\gamma+\delta) t}}{\gamma+\delta}+C
$$

where $C$ is an arbitrary constant. Simplifying

$$
K(t)=\frac{I_{0} e^{\gamma t}}{\gamma+\delta}+C e^{-\delta t}
$$

Since at $t=0, K=K_{0}$, we can evaluate $C=K_{0}-I_{0} /(\gamma+\delta)$. The constant is positive if the initial growth of investment is greater than the growth rate of the capital stock and vice-versa. ${ }^{6}$ Equation (8) has two terms. As $t$ grows large, the second term on the right, the transient part of the solution, gets smaller and eventually goes to zero. Thereafter, the solution consists of only the steady state part, the first term on the right, with the growth rate of the capital stock equal to the growth rate of investment, $\gamma$. The ratio of investment to capital stock is constant at $\gamma+\delta$. The fixed capital-output ratio ensures that output and the capital stock are growing at the same rate and thus the share of output devoted to accumulation remains constant as well.

The solution to this differential equation is general and it will be seen that the standard and structuralist models are special cases of it. If the rate of growth of investment is the same in the two models, the paths for the capital stock followed will be identical, as defined by equation (8). The structuralist and standard models differ in how the rate of investment is determined, but once established, the capital stock and output must follow the same path.

\footnotetext{
${ }^{5}$ Alternatively, if we knew the growth rate of investment, say from the SAM in the following period, we could determine the capital-output ratio. If for example, investment is growing at 4 percent per year and depreciation is 5 percent, $I / K$ must be 9 percent. If $\alpha$ can be read from the SAM, say at 18 percent of GDP, then the capital-output ratio would be 2 percent for steady growth.

${ }^{6}$ Proof: $C>0 \rightarrow K_{0}-I_{0} /(\gamma+\delta)>0 \rightarrow \gamma>\frac{I_{0}}{K_{0}}-\delta$. If the growth rate of investment is less than that of the capital stock, then the constant is negative and the growth rate of the capital stock is slowing down as the system approaches equilibrium.
} 
Moreover, so long as both the standard and structuralist economies pass through the same SAM and the rate of depreciation is the same, the steady-state path of output will also be the same. To see this, note that by definition, the rates of growth of investment and the capital stock are the same in the steady-state and thus $I / K$ must by the same as the models pass through the SAM. With the same investment, as read from the SAM, he capital-output ratios must then be identical. 7

But will $v$ and $\alpha$ remain constant in each model? The answer is yes in both cases, so long as there are constant returns to scale. In the structuralist model, the capital-output ratio is fixed by assumption, but it is also true that in the standard model, the capital-output ratio remains constant since capital and labor must be both growing at the same rate. To see that, consider figure 3. Let us say that the SAM above is for period 0. At the beginning of that period, there was available capital at level $K_{0}$ and labor at $L_{0}$. These factors combined to produce real output on isoquant $Q_{0}$. During the period, the SAM shows that investment at rate $I$ took place. With a given rate of depreciation, say that the capital stock increased from $K_{0}$ to $K_{1}$. If labor does not grow, output rises only to $Q_{1}$. The capital-labor ratio increases from $k_{0}$ to $k_{1}$. Because there is more capital per unit of labor, diminishing returns to capital sets in and output cannot grow in proportion to the capital stock. The capital-output ratio must then rise to something above the base level $v$. Only if labor grows in proportion to the capital stock, from $L_{0}$ to $L^{*}$ will diminishing returns be avoided. Assuming constant returns to scale, output will grow at same rate as the factors of production. The steady-state capital-output ratio remains constant for the standard model as well.

The distribution of factor income also remains fixed in both models. In the structuralist model, distribution is given and therefore independent of the rates of growth of capital and labor. For the standard model, figure 3 shows that when labor is constant at $L_{0}$, the wage-rental ratio rises from $(w / r)_{0}$ to $(w / r)_{1}$. But when labor expands proportionately, there is no change in the distribution of income between wages and profits. Factor demand grows at the same rate as factor supply, so the market-clearing factor prices remain fixed.

In steady-state equilibrium, there is evidently little to distinguish the two models. The essential difference must then lie in how investment behaves as the models approach the steady state.

\subsection{Investment growth}

It could be argued that taking the rate of growth of investment as the independent variable of the system begs one of the central questions of economic analysis, viz. how is $\gamma$ determined. Keynes famously held that since investment undertaken by individual agents depends upon irresolvable uncertainty about the future, aggregate investment must be taken as the independent variable of the macroeconomic system. One might object that even with "animal spirits" in control of the path of investment, current period output must, at a minimum, impose an upper bound on current investment. But since current output depends on the Keynesian multiplier, the system would seem to support any rate of growth of investment. If output did constrain the structuralist model, the difference would shrink even outside the steady state, since the fraction of output devoted to accumulation is not explained within the standard model. But output does not constrain investment in the SGM for two fundamental reasons: first, since the model is "demand driven" any spare output, in excess of what is needed for consumption and accumulation, would not have been produced in the first place. And, of course, output that was never produced cannot be saved. Thus, the SGM provides a highly subjective account of the accumulation process, dependent for the most part on how agents perceive the future in regard to profitability. Investment growth is in no way "structural" and requires deep thinking, not only about agency, but about how the agents interact. Keynes's arresting analogy of "beauty contest", in which investors seek shares in firms only because they believe others will find them attractive is the key. Clearly, agency rather than structure rules here, but not the atomistic agency of the standard approach. Second, output cannot determine investment because the subjective nature of the investment decision would

\footnotetext{
${ }^{7}$ Let $v^{\prime}$ be the capital-output ratio for the standard model and $v$ be that of the structuralist model. From equation 2 we have

so if they pass through the same SAM, $v=v^{\prime}$.

$$
\frac{\alpha}{v^{\prime}}=\frac{\alpha}{v}
$$
}




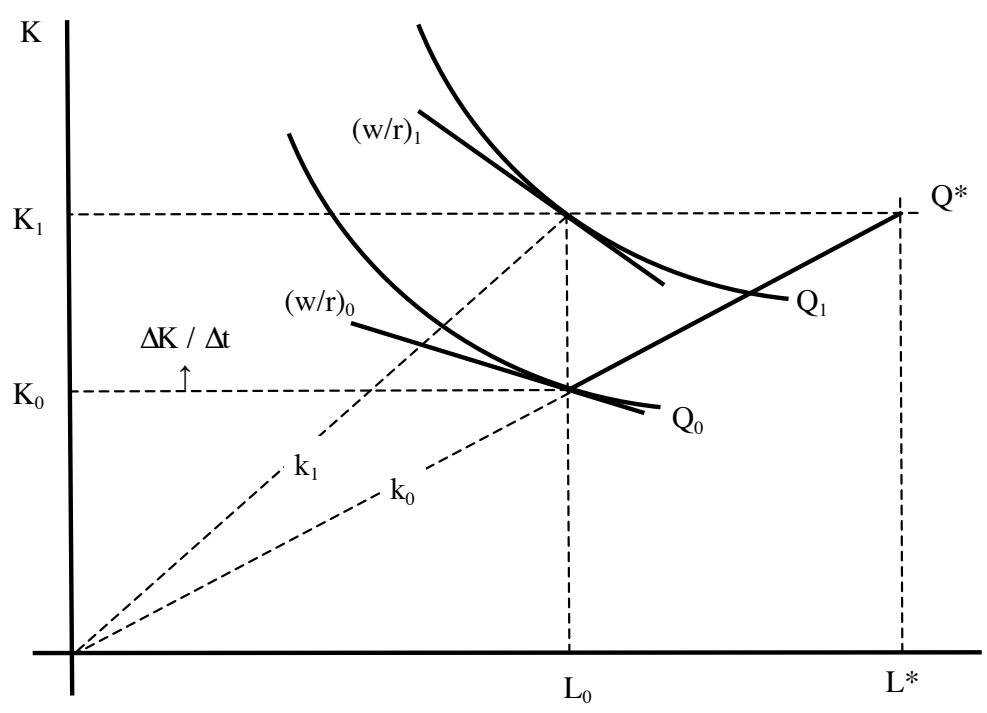

Figure 3: Adjustment process

not allow it. As just noted, perceptions of profitability are key to the structuralist account of investment, and the additional capacity that would have been generated by spare output would surely reduce the inducement to invest, which itself would prevent any spare output from arising in the first place. Since structuralists do not attempt to model the "beauty contest" in any serious way, it follows that for the SGM, investment must remain the independent variable of the system 8

Paradoxically, the standard model relies even more on structure to close the loop. There, investment growth depends on output, which in turn is limited by the growth of the factors of production. The model then depends on adjustments in the functional distribution of income to ensure that any spare capacity be fully utilized. Investment growth is endogenized, but the model still depends, in a fundamental way, on a variable given outside the system, the rate of growth of employment.

The standard model can be solved for the time path of the capital stock and we now do so in a way that will be easily compared to that of the SGM above. With the investment to output ratio given, it is a simple matter to rewrite equation (4) in continuous time as

$$
\frac{d K}{d t}+\delta K=\frac{\alpha}{v(K)} K
$$

where $v$ is expressed as a function of the capital stock to allow for out-of-equilibrium dynamics, as depicted in figure 3 .

Note that the path of $v(K)$ depends crucially on what happens to labor and how labor is substituted for capital along the path. This means that we must have some functional form to describe the curvature of the isoquants in figure 3 . Take, for example, the standard Cobb-Douglas production function. There the capital-output ratio is given by

$$
v=\left(\frac{K}{L}\right)^{(1-\beta)}
$$

\footnotetext{
${ }^{8}$ It is possible to define a capital constrained SGM for which the two Keynesian principles are held in abeyance, such that income is determined by the time path of the capital stock. We will see shortly, however, that it is not possible to have a constant fraction of output devoted to accumulation in the capital-constrained model without introducing instability. See section 3.6 below.
} 
where $\beta$ is the elasticity of output with respect to the capital stock, that is, the exponent on the capital stock in the Cobb-Douglas equation or share of capital in total output. Assume that we know the time path of $L$ as $L_{0} e^{n t}$, with $n$ as the rate of growth of labor. Substituting equation (10) into equation (9), we have

$$
\frac{d K^{\prime}}{d t}+\delta^{\prime} K^{\prime}=L_{0}^{\prime} e^{n^{\prime} t}
$$

where $K^{\prime}=K^{1-\beta}, \delta^{\prime}=(1-\beta) \delta, L_{0}^{\prime}=\alpha(1-\beta) L_{0}^{1-\beta}$ and $n^{\prime}=n(1-\beta)$. The transformation is made in order to emphasize the basic similarity with equation (7). Note that the variables on the left-hand side are only slightly transformed versions of the originals, while on the right labor has taken the place of investment 9

Since equations (11) and (7) have the same form, it follows that the solution will be the same as well. Therefore, we can immediately write

$$
K^{\prime}(t)=\frac{L_{0}^{\prime} e^{n^{\prime} t}}{n^{\prime}+\delta^{\prime}}+C^{\prime} e^{-\delta^{\prime} t}
$$

where $C^{\prime}$ is a constant similar to $C$ in equation (8). Since the rates of growth $\hat{K}^{\prime}$ and $\hat{K}$ are the same by virtue of the constancy of $\beta$, we conclude that the constant $C^{\prime}$ is positive if the adjusted rate of growth of labor, $(1-\beta) n$ is greater than the rate of growth of the capital stock and vice-versa.

Despite their having different drivers, investment growth in the case of the SGM and labor for the standard model, the models are strikingly similar. Both rely on the exogenous determination of crucial variables of the system, parameters that are taken as given rather than modeled explicitly as an agent-based decision- making process.

\subsection{Transition to the Steady State}

We have seen that the two models are equivalent in the steady state, but how do they behave in the transient part of the solution? Figure 4 shows that in fact the two models approach the steady state in equivalent ways, with both $C$ and $C^{\prime}>0$. For the structuralist model, the horizontal line is the rate of growth of investment. That same line represents the adjusted rate of growth of labor, $n(1-\beta)$ for the standard model. Again, the similarity is evident; in both models, the capital stock adjusts to an exogenously given rate of growth. As we have seen, the major difference is that the exogenous factor in the case of the standard model, $L$, drives the growth rate of investment through the production function. In the Cobb-Douglas production function the elasticity of output with respect to labor growth is $1-\beta$. Since investment and output grow at the same rate, investment in the standard model must then grow at $(1-\beta) n$. In figure 4 these are equal by construction; therefore, the time path of the capital stock must be the same for both models. Figure 4 shows the time path of the capital stock. How does output respond in each of the two models? In the standard model, output grows as a weighted average of labor and capital stock growth, with the weights as the marginal products of the two factors of production. We then have

$$
\hat{Q}=Q_{K} \hat{K}+Q_{L} \hat{L}
$$

where subscripts indicate partial derivatives. With $C^{\prime}>0$, labor growth is faster than capital growth, so output growth is somewhere in between for the standard model along the time path. In the SGM, however, the fixed capital-output ratio ensures that output growth is always exactly equal that of the capital stock. If the capital stock approaches investment growth from below, then output must be growing more slowly than $\gamma$ and vice-versa if from above. In figure 4 , then, the standard model must be growing faster than the SGM, and this turns out to be a fundamental difference between the two approaches.

It is easy to see how this difference arises. In the SGM, the rate of growth of the labor force must exceed $\gamma$, otherwise the labor constraint would eventually bind. Normally, surplus labor accumulates without having

\footnotetext{
${ }^{9}$ But why is labor multiplied by the factor $(1-\beta)$ ? One way to think of this is that in the SGM, investment had a direct effect on $K$, but now labor growth must be filtered through the production function before it affects the growth of the capital stock. The production function must be reduced by $\alpha$ to get to investment. The growth rate $n$ is reduced for the same reason: the impact of labor growth on capital accumulation is diminished by its co-participation in production.
} 


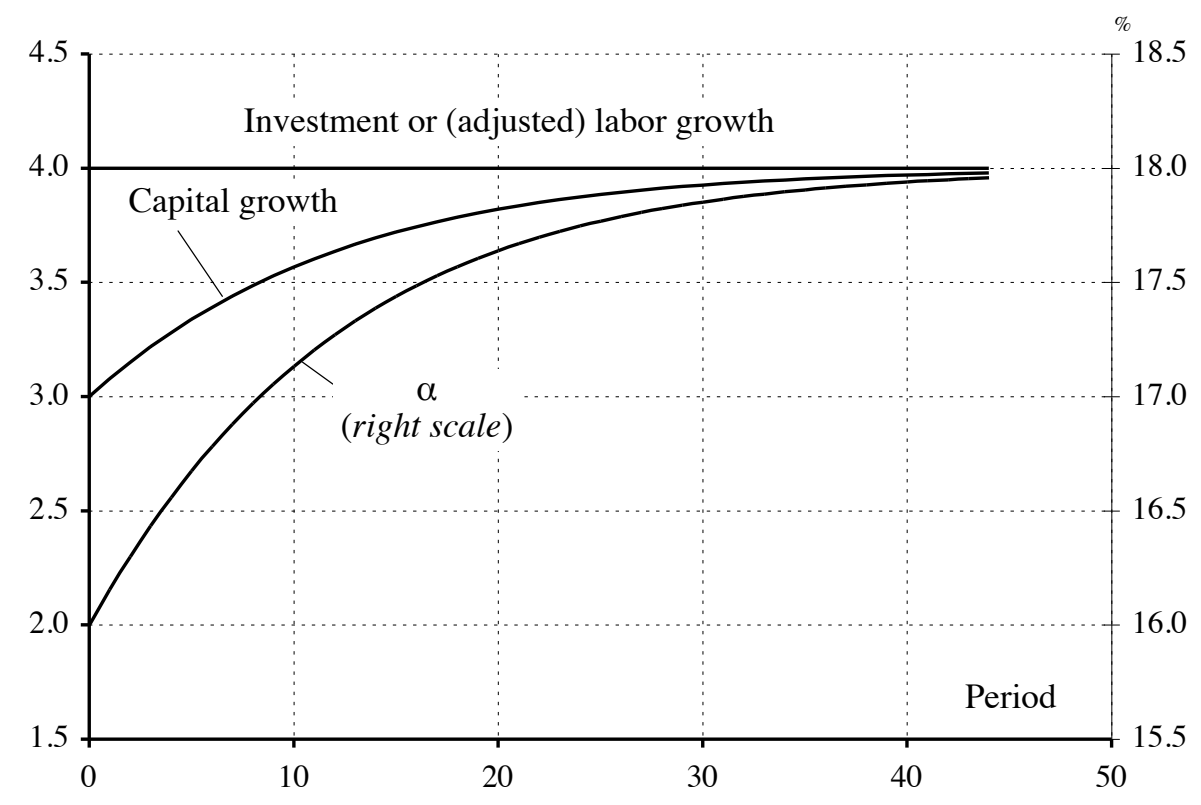

Figure 4: Adjustment to the steady state in the SGM and standard model

any effect on output whatsoever. The standard model, by contrast, economizes on the scarce resource, capital, and will progressively switch to a more labor-intensive growth path. With the same addition to capital stock, but more labor, its firms will produce more than SGM. With more output available to invest, the rate of growth of investment will accelerate. This transition will continue until the rate of growth of the capital stock is just equal to that of the labor force. If the two models pass through the same SAM on the way to the steady state, output per unit of capital will necessarily be higher after the transition in the standard model. Evidently, output lags behind in the SGM because it does not fully utilize available labor. We shall see below that the SGM will lag even further if it fails to fully utilize capital, that is, if capacity utilization is less than one.

\subsection{Stability}

With the growth rate of investment $\gamma$ taken as given, the SGM converges nicely to a steady state, just as the standard model. In the standard model, $\alpha$ is usually taken as fixed, as the savings rate. In the SGM, however, the ratio of investment to capacity output, $Q$, must be rising over time for $C>0$ (and vice-versa). Since $\alpha=I / Q$ and $Q$ grows at the same rate as $K$ because of the assumption of the fixed capital-output ratio, it must be the case that $\alpha$ rises to an asymptote, as seen in figure 4

This movement of $\alpha$ is crucial to the stability of the SGM. If $\alpha$ were constant, the inflow of investment into the capital stock would increase with the capital stock in exact proportion. Since depreciation is also a fixed percentage of the capital stock, the capital growth rate would be a constant $\alpha / v-\delta$. It is immediately obvious that there is no mechanism to bring this growth rate into equality with $\gamma$, unless by fluke. This is the famous "knife-edge problem" that goes back to Harrod (1937). In a capital constrained SGM, a fixed percentage of output cannot be plowed back as investment unless the model is already in the steady state.

This raises the question of why must $\gamma$ be given. Could the level of investment be given instead? Clearly, if the level of investment were a given constant, then its growth rate would be zero. The economy would then be in a stationary state with capital stock growth equal to zero. But what if investment were given as, 
say, a fraction of capacity output? In that case, we would have the right-hand side of equation (6) constant, which would immediately imply $\hat{I}=\hat{K}$. The model is then already in the steady state. Is the system stable in the sense that if $K$ departs from the growth path momentarily, growing either faster or slower than its steady-state value, will forces emerge to return it to the steady state? The answer to this question is, unfortunately, no. If the capital stock were to rise, then so too would capacity. If investment stood in fixed proportion to capacity, it would also rise and $\hat{K}$ would increase. Now investment and the capital stock are again growing at the same rate and the economy is in a steady state, but different from the one from which it momentarily departed. Apparently, for a meaningful transient part of the solution, the rate of growth of investment, not its level, must be given.

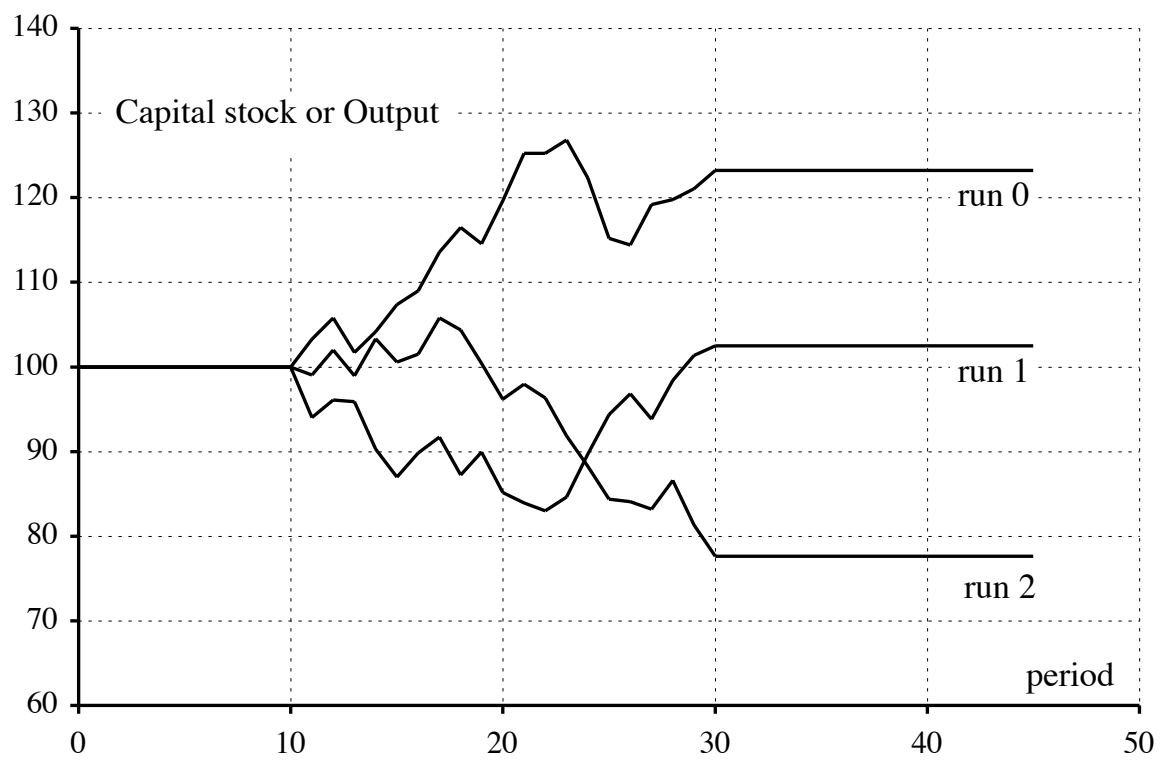

Figure 5: Instability in the capital-constrained SGM

The instability is illustrated in the simulations of figure 5 . There the economy is in a stationary state for the first ten periods. Between periods ten and thirty, a random shock is introduced on $\alpha$, altering the rate of growth of the capital stock. It is clear from the figure that the shock sends the economy on a random walk. In the thirty-first period, the shock is removed and the economy stabilizes again, but at significantly different levels of the capital stock. This is the permanent effect of changes in the parameters of the model that is much discussed in the literature (Skott, 2008). 10

We conclude that the standard model achieves stability through flexibility in the capital-output ratio while the capital-constrained SGM does the same by way of a variable $\alpha$. We have for the steady state

$$
\frac{\alpha}{v}-\delta= \begin{cases}n^{\prime} & \text { if standard and } \alpha \text { constant, } v \text { variable } \\ \gamma & \text { if capital constrained SGM } v \text { constant, } \alpha \text { variable }\end{cases}
$$

It could be argued that both models produce unrealistic results. In the standard model, capital intensity will decline until all those willing to work at the market wage rate are employed. This is, of course, seemingly inconsistent with the experience of developing countries, prior to the Lewis turning point. High

\footnotetext{
${ }^{10}$ Some structuralists view this as an advantage of the methodology, that there is path dependence in the model in that where the economy ends up depends on the path taken (Dutt, 2005). See section 4.3 for further discussion.
} 
unemployment rates can persist for decades, despite low wages and surplus labor. The structuralist model, on the other hand, does produce results consistent with high levels of unemployment. The problem is that with a fixed capital-labor ratio, employment must grow at the same rate as investment $\gamma$. With $\gamma$ less than $n$, the unemployment rate goes to infinity. At the end of every period, more labor will have accumulated than the capital necessary to employ it.

\subsection{Variable investment growth}

So far it has been assumed that in the structuralist model, $\gamma$ is constant. A constant $\gamma$ is consistent with the Keynesian notion that investment is the independent variable of the system, but some SGMs allow $\gamma$ to vary, at least within a narrow range. In this section, we show that this is only feasible to the extent that $\gamma$ is bounded. If the rate of growth of investment is higher than that of the capital stock, $\gamma$ must be bounded from above. If $\gamma$ is less than $\hat{K}, \gamma$ must be bounded from below.

The most common arguments in the $\gamma$ function are capacity utilization, $u$, and some measure of income distribution, either the wage-rental ratio or the profit share. We address these sequentially beginning with capacity utilization. If there is no trend in $u$ in the long run, it follows that $\hat{Y}-\hat{Q}$. Any variation in $\gamma$ due to changes in $u$ can then only occur on the transient path ${ }^{11}$ Before the steady state equation (6) shows that $\hat{u}$ can only be non-zero when $\gamma$ differs from $\hat{K}$. When the former exceeds the latter, capacity utilization is rising, and vice-versa ${ }^{12}$ Hence, a variable rate of investment growth along the adjustment path does not upset the comparability of the two models in the steady state undertaken above.

Outside the steady state, the $\gamma$ function is almost always assumed to rise with $u$; the exception is when commodity, labor or financial costs rise as well, reducing the rate of profit and thus the incentive to invest, even though extra capital is needed. For the moment, assume

$$
\gamma=\gamma(u) \text { with } \gamma^{\prime}(u)>0
$$

As utilization rises, employment also increases and with it savings of firms or by households for retirement or to educate their children. Rising demand provides an incentive for firms to expand investment, to add productive capacity or accumulate inventories. But the first effect on savings must be stronger than the second on investment. Were it not, an increase in investment would itself raise capacity utilization, which would, in turn, raise investment producing an explosive cycle. Capacity utilization would quickly exceed its unitary bound. That consumption does not grow in proportion to income is known as the standard Keynesian short-run stability condition and is usually assumed in SGMs (Taylor, 1983). Hence we have a continuous approximation

$$
I=I_{0} e^{\gamma(u) t}
$$

where $\gamma$ must be defined by a functional form that follows

$$
\gamma= \begin{cases}\bar{\gamma} & \text { if } u=1 \\ \gamma(u) & \text { if } u<1\end{cases}
$$

where $\lim _{u \rightarrow 1} \gamma(u)=\bar{\gamma}$.

If $\gamma$ depends on capacity utilization, then the investment growth line could shift up as shown in figure 6 . For the first ten periods, $\gamma$ is 3 percent, but then increases to 4 percent. The figure shows a smooth transition as capital stock growth also rises to 4 percent. In the process, capacity utilization rises from 80 to 90 percent.

\footnotetext{
${ }^{11}$ It makes no conceptual difference whether full capacity utilization is defined as $u=1$ or $u=\bar{u}$, where the latter is defined as some "normal" or "desired" utilization rate. Lavoie et al. (2004) have argued that the desired rate can be determined endogenously, but in each case the long-run equilibrium is defined exogenously. Actual utilization deviates from desired by some rule that reduces desired utilization until it is consistent with the expected $\gamma$. Skott (2008) notes that this generates a stable two-equation system that converges to some $\gamma$ and $\bar{u}$. But this adds nothing to the determination of $\gamma$ since whether it converges to one or some other given number makes no difference to the necessity that it converge.

${ }^{12}$ While it would be formally possible to have $\hat{u}$ just equal to the difference between $\gamma$ and $\hat{K}$, this cannot persist in the steady state since $u$ would display a trend. Since $u$ is bounded by one, a trend in $u$ seems infeasible. Critically damped cycles are, however, possible and would give rise to cyclical behavior of $u$.
} 


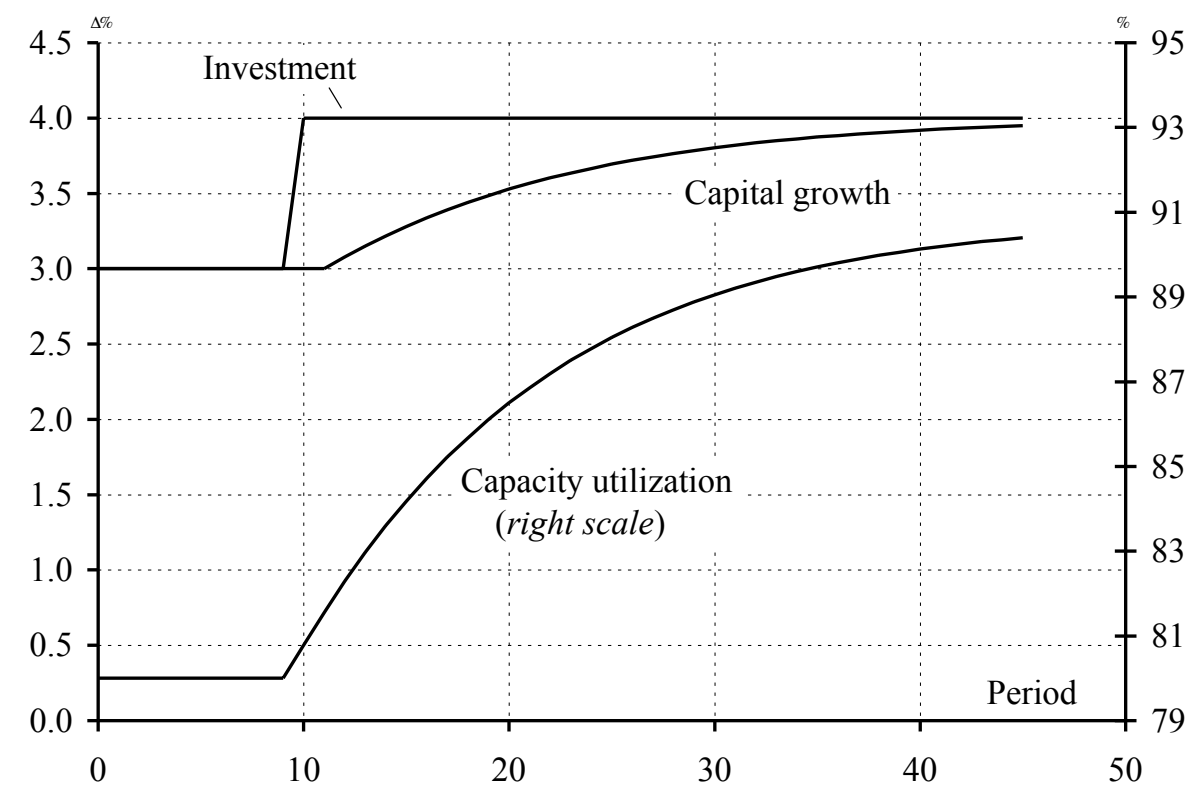

Figure 6: Growth of investment depends on capacity utilization

As $u$ approaches one, $\gamma$ approaches its limiting value, $\bar{\gamma}$. Thus a variable $\gamma$ is consistent with the basic SGM, so long as it has an upper bound as described in equations (14).

One way to ensure that equations (14) are indeed satisfied is to use the discrete logistic function

$$
\gamma_{t+1}=\phi \gamma_{t}\left(1-\gamma_{t}\right)
$$

where $\phi$ is an adjustment parameter. When $\gamma$ is small, the quadratic term is close to zero and $\gamma$ approximates an exponential growth path. If $C>0$, an increase in the growth rate of investment causes the growth rate of the capital stock to accelerate, but not proportionately, according to equation (4). With a constant $\alpha$, actual output does increase proportionately and, thus, capacity utilization rises. This in turn causes $\gamma$ to rise ${ }^{13}$ The logistic equation ensures that $\gamma$ will not rise indefinitely. As $\gamma$ approaches its maximum, $\bar{\gamma}$, growth in $\gamma$ slows. Figure 7 shows a family of curves that could describe the adjustment path of $\gamma$. They start with different initial values, the lowest at $\gamma(0)=0.01$.

The logistic equation can be calibrated to give $u=1$ at the steady-state growth rate of investment as follows. Taking account of equation (6) with $u=1$, the upper bound must be

$$
\bar{\gamma}=\frac{\alpha}{v}-\delta .
$$

And now convergence is simply a matter of calibrating the logistic function to this bound. The logistic difference equation has a fixed point at

$$
\gamma_{t}=\phi \gamma_{t}\left(1-\gamma_{t}\right)
$$

If $\gamma$ is taken a s given at $\gamma=\bar{\gamma}$, we need only solve for $\phi$ to calibrate the model; we have

$$
\phi=\frac{1}{1-\bar{\gamma}}
$$

\footnotetext{
${ }^{13}$ When $C<0$, the process unfolds in reverse and $u$ falls continuously.
} 


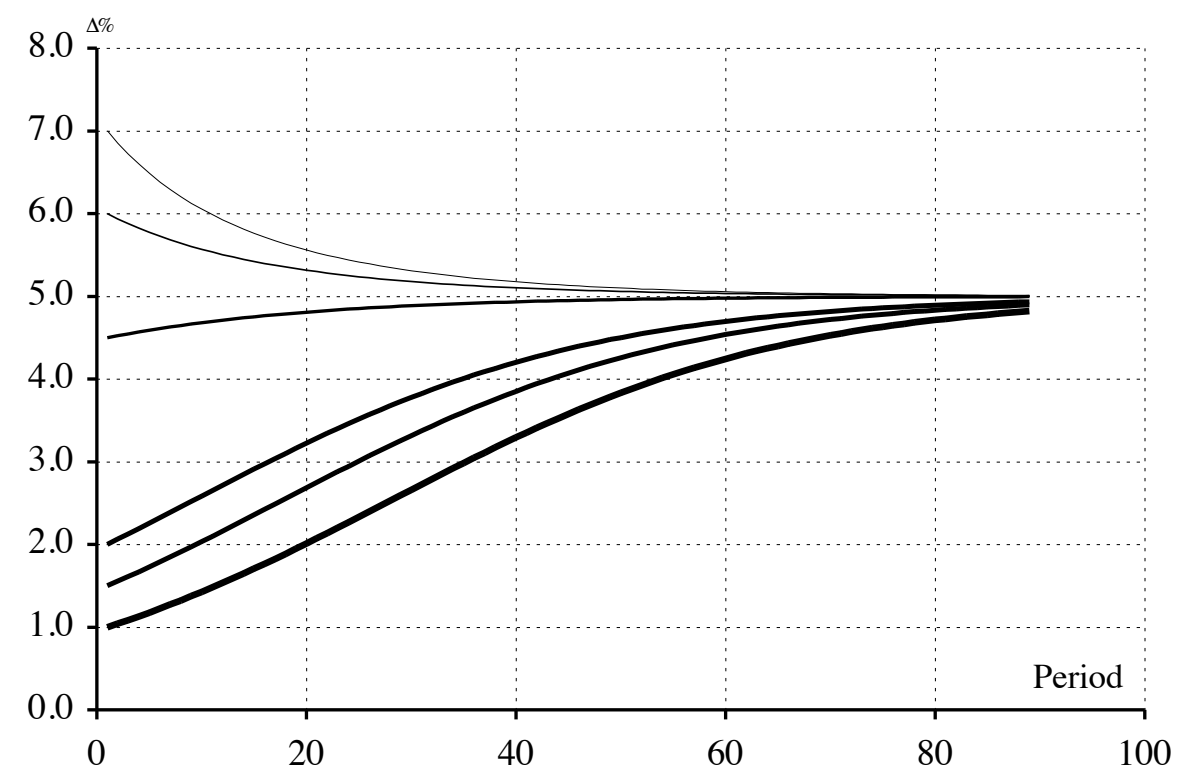

Figure 7: Logistic equation for $\gamma$

So we need not specify a constant rate of growth of investment for a coherent SGM; all that is necessary is a steady-state rate of growth of investment and the capacity utilization term generates no instability. Further if $\bar{\gamma}$ is set to equal the rate of growth of the labor force, $n$, the standard model and SGM converge to the same steady-state level of the capital stock and look very similar indeed. The SGM allows for less than full capacity utilization along the transient path yet converges to long-run equilibrium with the rate of growth of the capital stock equal to growth of the labor force. This would eliminate the main objection to the SGM noted above, viz., that the rate of unemployment is unbounded in the long run ${ }^{14}$

\subsection{Example}

In this example, we calibrate an investment function that follows a logistic path such that $u=1$ when the economy is growing at 5 percent. Figure 8 shows the trajectories for the growth rate of investment and capital stock, together with capacity utilization when $\gamma$ grows according to the logistic function. The model passes through the base SAM, in table 2, with an initial capacity utilization of 0.8 , and depreciation rate, $\delta$ $=0.05$. The share of investment in output is calibrated from the SAM at $\alpha=0.2$. The fixed point of the discrete logistic function is $\phi=1.0526$ so that investment growth converges to $\bar{\gamma}=0.05$. In the figure, the $\gamma$ function of the model follows the lowest of the family of curves in figure 7], that is, with an initial value of $\gamma(0)=0.01$. After 80 periods, there is still a gap between investment growth and the capital stock, but it narrows and capacity utilization converges toward one.

\footnotetext{
${ }^{14}$ The logistic approach is but one way to impose the order on the $\gamma$ function that all SGMs must do. It is, for example, possible to make $\gamma_{t}$ follow a path that explicitly depends on $u$, but with the effect dying out asymptotically. This can be accomplished with the negative exponential function.

$$
\gamma=\bar{\gamma}\left[1+\phi\left(e^{-1}-e^{-u}\right)\right]
$$

where $\phi$ is an adjustment factor. Note that when $u=1$ the rate of growth of investment is $\bar{\gamma}$. Simulation of a model that employs this functional form produces results similar to figure 6. except that there is some curvature in the investment growth rate.
} 


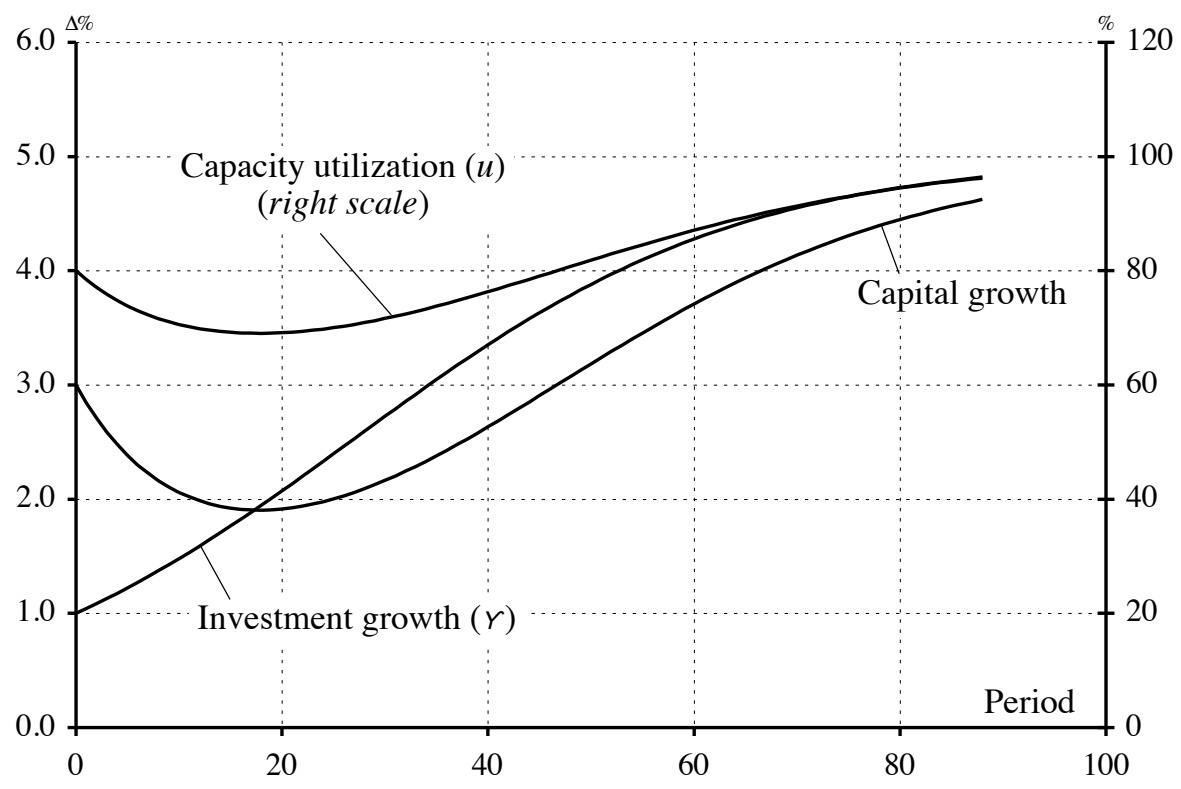

Figure 8: Logistic equation for $\gamma$

Table 2: A Social Accounting Matrix

\begin{tabular}{lcccc}
\hline & Firms & $\begin{array}{c}\text { Household } \\
\text { Investment }\end{array}$ & Total \\
Firms & & 400 & 100 & 500 \\
HHolds & 500 & & & 500 \\
Savings & & 100 & & 100 \\
Total & 500 & 500 & 100 & \\
& & & & \\
\hline
\end{tabular}

Source: Author's calculations. 


\subsection{The investment constrained SGM}

So far we have argued that a fully coherent SGM must take the rate of growth of investment as the independent variable and that there are a variety of ways in which variable capacity utilization can be built into the model. Since a time path for $\gamma$ implies a time path for the share of investment in GDP, $\alpha$, why not simply take $\alpha$ as given and let the rate of growth of investment and capital stock adjust? In the capital constrained SGM, we have seen that this deprives the model of a meaningful transition to the steady state. Is the same true when the model is investment constrained, that is, when the rate of capacity utilization is variable?

To begin to address this question, rewrite equation (4) as

$$
\hat{K}=\frac{I}{K}-\delta=\frac{\alpha u}{v}-\delta
$$

Once capacity utilization is less than full, no constraint binds. Is it then meaningless to talk about an upper bound on investment given by how much the economy produces? The usual account is that investment growth simply adjusts to subjectively determined perceptions of future profitability. Typically the investment function takes the form

$$
I=(a+b u) K
$$

where $a$ and $b$ are given constants that (supposedly) capture "animal spirits" and the responsiveness of investment to capacity utilization. Substituting the definition of capacity utilization

$$
I=[a+b(Y / Q)] K
$$

but since $Y=I / \alpha$ and $Q=K / v$, we have

$$
I=\frac{a}{1-b v / \alpha} K
$$

Thus, if $\alpha$ is constant, it is immediately evident that $\hat{I}=\hat{K}$, the condition for steady growth. Again, the model seems to be stuck in the steady state from birth, at least as configured in equation (16). Any change in $u$ or $\alpha$ will cause the model to move to a new equilibrium, which will again be a steady state, as illustrated in figure 6 above. Introducing variable capacity utilization does not alter the character of the SGM, so long as $\alpha$ is constant.

So if $\alpha$ is indeed variable, how might it be determined? First, there are obvious bounds on $\alpha$ that must be respected; in particular capacity utilization must be nonnegative with an upper bound of 1 . Thus $I / K$ must be in the range corresponding to $u=[0,1]$

$$
(a+b) \geq \frac{I}{K} \geq a
$$

which implies that $1 \geq \alpha \geq(a+b) v$. The smaller the level of $\alpha$ the larger is $I / K$, so $(a+b) v$ puts an upper limit on $\hat{K}$. Since $\gamma$ cannot exceed $\hat{K}$ in the steady state, full capacity utilization provides an upper limit on investment growth.

Stability is more problematic. In the SGM output adjusts to investment according to the rule that if saving exceeds investment, output falls and when investment exceeds savings, output rises. Stability is ensured by the restriction that savings responds to an increase in capacity utilization more than investment. Savings is usually taken to be a function of output, so might the stability condition effectively put a bound on the $\gamma$ function? This possibility is discussed by Dutt (1997). Consider a steady-state equilibrium in which capacity utilization is less than one. An instantaneous uptick in capacity will increase $\gamma$ and cause $\hat{K}$ to accelerate. What forces are available to return the capacity utilization to its initial level? Nothing really, as we have seen, the higher $\gamma$ will cause the capital stock to adjust to a higher $I / K$ in a new steady-state 
equilibrium. The only available variable in the model that could restore the initial capacity utilization is $\alpha$. Differentiating equation (17), with $\alpha$ variable

$$
\hat{I}=\frac{-b v}{\alpha-b v} \hat{\alpha}+\hat{K}
$$

where the denominator of the first term on the right is positive by Keynesian stability condition. It now is obvious that $\alpha$ must increase so that the rate of growth of investment falls. The underlying economic reasoning for why this must occur is not usually spelled out, but the impact is clear: for stability, a rise in capacity utilization in the steady state must cause $\gamma$ to fall even though this is inconsistent with the assumed motivation for investment, that is, that investment respond positively to higher capacity utilization. If investment rose faster than output, $\alpha$ would increase and the model would move to another equilibrium as discussed above.

We conclude that the standard stability condition does indeed effectively provide a bound for $\gamma$, but does so in a way that is no less arbitrary than exogenously imposing an upper bound on the $\gamma$ function, as for example, does the logistic function studied above. Moreover, the standard stability condition similarly deprives the system of any meaningful adjustment process to the steady state, since it ensures that any equilibrium is a steady-state. Imposing a stabilizing path on $\alpha$ means that any deviations from the equilibrium level of capacity utilization will be restored. The short-term stability condition is at once a long-run stability condition, since the long run for the SGM is nothing more than a sequence of short runs. This certainly distinguishes the two models, since in the standard model, the transient part of the path can last for many periods, often in the 100-150 range. It must be concluded that the steady state plays a much bigger role in the overall character of the SGM relative to the standard model.

It also seems fair to say that capacity utilization in the SGM is not a fundamental determinant of investment since its range of variation is necessarily narrow. Changes in capacity utilization provide an extra burst of growth when there is an independent investment function. But unlike diminishing returns in the standard model, the independent investment function works the wrong way, causing instability in the adjustment process. The SGM is now clearly distinguished from the standard model in important respect. The second main difference, its treatment of labor, is discussed in more detail in the following section.

\section{The distribution of income}

The functional distribution of income may provide the solution to the stability problem, reducing the incentive to invest as factor supplies become less abundant, raising costs and thereby reducing profit per unit of capacity. In the standard model, the treatment of the functional income distribution is straightforward. If the rate of growth of one factor exceeds that of the other, its relative return falls. Profit maximization ensures that more of the abundant factor will be employed in production. Diminishing returns guides the combination of factors to its correct level, with the marginal increment in costs equal to the marginal increase in the value of output for each factor. Income distribution thus plays a crucial role in the standard model, regulating the rate of growth of the capital stock so that it eventually comes to equal the growth rate of labor.

Normally investment in the standard model depends on output, but when capital accumulation is linked to profit rather than output as a whole, the standard model adjusts more rapidly to differences in the relative rates of factor growth. If labor is growing too fast, the marginal product of capital increases and with it the mass of profits from which investment flows (and vice-versa if labor is growing too slowly). Rather than get in the way, income distribution assists the equilibrating process.

In the SGM, income distribution does not always move in a beneficial way. Say, for example, that labor growth outstrips that of capital. With wages determined outside the model, there is no natural mechanism by which capital accumulation can accelerate to accommodate more abundant labor. The fixed relationship between capital and output prevents stepped up utilization of labor. In the worst case, labor accumulates ad infinitum, as noted above, while capital accumulation proceeds unfazed. 
In the standard model, factor shares are usually taken as given, either directly or through a calibrated elasticity of substitution. In the SGM, initial factor shares are calculated from the base SAM. The factor shares in the SAM also determine mark-up, $\tau$. This results from the simple price equation in the SGM. This usually takes the form

$$
p=(1+\tau) w l
$$

where $p$ is the price level and $l$ is unit labor demand. Thus, if the rate of profit, $r$, is total profit divided by the value of capital stock

$$
r=\frac{\tau w l Y}{p K}=\beta \frac{u}{v}
$$

where $\beta$ is the share of capital

$$
\beta=\frac{\tau}{1+\tau}
$$

so that fixing the mark-up determines the profit share and vice-versa. Profitability depends on both the profit share and capacity utilization. The wage-rental ratio, $\omega=(w / p) / r$, for the SGM can then be expressed as

$$
\omega=\frac{1-\beta}{\beta} \frac{v}{l u} .
$$

As either the profit share or capacity utilization rises, the wage-rental ratio falls. A rise in $u$ in turn implies that $\hat{I}$ must be greater than $\hat{K}$. Once at full capacity utilization, the wage-rental ratio is fixed and again the SGM closely resembles standard model. In the latter model, with Cobb-Douglas technology, the wage-rental ratio depends on the fixed capital-labor ratio and the shares of income of the factors of production

$$
\omega=\frac{(1-\beta)}{\beta} k
$$

where $k=K / L$. But since $v / l$ is also $k$, equations (18) and (19) give the same value for $\omega$ when $u=1$.

Thus, with a constant $\beta$, the wage-rental ratio normally declines with $u$. But the profit share might also erode due to increased costs as utilization increases. If so, $\omega$ can increase as the model approaches the steady state, and even overwhelm the effect of rising capacity utilization. Rising costs would then reduce $\gamma$, enhancing the stability of the system. In that case, SGM would come to more closely resemble the standard model, with class conflict replacing diminishing returns to ensure the stability of the system.

Bhaduri and Marglin (1990) note that any increase in the real wage will depress the profit margin, that is, the mark-up, and thus the profit share. Aggregate demand will rise or fall depending on the impact of the falling $\beta$ on investment. A lower profit share will weaken the incentive to invest, so that a higher wage rate increases consumption, but reduces investment. The balance of these forces determines the effect of an increase of the real wage on output. The derivative $u_{\beta}$ is said to depend on deep structural features of the economy called, somewhat infelicitously ${ }^{15}$

$$
u_{\beta}= \begin{cases}<0 & \text { stagnationist or wage-led } \\ >0 & \text { exhilarationist or profit-led. }\end{cases}
$$

Since neither $\beta$ nor $u$ can have a trend, these structural features only matter in the short run. Moreover, exhilarationist configurations are stabilizing but stagnationist ones are not. To see this, consider an economy in the steady state with full capacity utilization. Now introduce a negative demand shock, so that $u<1$. This lowers employment and output. If there is a strong investment response to the rising profit share, the economy will return to full capacity utilization. If the economy is stagnationist, the demand shock is more likely to be permanent and capacity utilization will remain below one on a new steady growth path.

\footnotetext{
${ }^{15}$ The distinction does not normally arise in the standard model, but it can. If investment is taken to be a share of profits, as it is for example, in its golden rule version, then the standard model is by definition exhilarationist or profit led (Barrow and Sala-i-Martin 2004). But if investment rises with the share of labor, then the standard model can also be stagnationist. The usual way in which the standard model is designed produces neither result, since investment is a fraction of total output and is not responsive to changes in its distributive components.
} 
The theory of how the profit-share moves is not well defined in the structuralist framework. It is not, for example, tied to the capital-labor ratio as in the standard model. There might be a "target" $\omega$, that corresponds to a "normal" profit share that occurs at full capacity utilization, but it is not clear how that target is determined or, in particular, why it would be respected ${ }^{16}$ It sometimes argued that $\omega$ is given by some exogenous process, such as the "class struggle," or that the real wage is fixed by some biological minimum, as in the classical Marxian model. There, increases in the share of profits cannot be tolerated, since starvation would reduce the supply of workers, eventually causing the labor constraint to bind. Since the labor constraint does not bind in the structuralist model, it follows that $\beta$ is exogenously bounded at some upper limit.

An early SGM that employs a variable profit share is due to Taylor (1983). In this model, labor is initially in excess supply, but then eventually becomes scarce, driving up the wage as capacity utilization nears one 17 Investment growth then converges to its steady-state equality with capital stock growth. The key to the stability of this model is to make investment more sensitive to the profit share than to capacity utilization so that near full capacity utilization $\gamma$ falls.

As in the previous section, investment is first defined as a level rather than by way of its growth rate $\gamma$

$$
\frac{I}{K}=f(\beta) \text { or } \gamma=\hat{f}+\hat{K}
$$

where $\hat{f}$ must be equal to zero in equilibrium. Accumulation is set as a fraction of profit, which is in turn a fraction of income. Practically, this amounts to the same thing as setting $\alpha$, since the fraction of profits devoted to accumulation is usually taken as a fixed and given constant. Thus, the multiplier depends only on the profit share $\beta$, which is distinguished from $\alpha$ as a share of total output 18

With the multiplier in hand and the constant labor coefficient, $l$, employment relative to full employment $\bar{L}$ can be defined as

$$
L / \bar{L}=l \frac{I}{\beta \bar{L}} .
$$

where the fully employed labor force is assumed to be growing at some constant rate $n$. Substituting equation 20 normalized by $\bar{L}$

$$
\frac{L}{\bar{L}}=l \frac{f(\beta) k}{\beta} .
$$

where $k=K / \bar{L}$. The crucial assumption is that as the employment fraction approaches one, labor's improved bargaining position causes the share of profits, $\beta$, to fall. Thus the equation of motion for $\beta$ is

$$
\dot{\beta}=\theta\left[1-l \frac{f(\beta) k}{\beta}\right]
$$

with $\theta>0$ as the adjustment coefficient. Taylor notes that there must be a "strong positive investment response" for stability, and we shall see that this is indeed true. As $\beta$ increases, $f(\beta) / \beta$ must increase, rather than fall, if employment is to rise. For employment to increase with a rise in profit share requires, then ${ }^{19}$

$$
\frac{d[f(\beta) / \beta]}{d \beta}=\frac{\beta f^{\prime}(\beta)-f(\beta)}{\beta^{2}}>0
$$

\footnotetext{
${ }^{16}$ One argument is that competition, domestic or foreign, imposes limits on the movement of $\omega$, which in turn implies limits on the profit share. Another is that profit and wage shares are structurally determined and evidence from the historical record is adduced to support the idea that they are constant and do not fluctuate much. This argument is somewhat self-referential since shares cannot, by definition, have a time trend.

${ }^{17} \mathrm{Cf}$. $\operatorname{Ros}(2003)$ who uses imported inflation to same effect, arresting the growth in investment as capacity utilization nears one.

${ }^{18}$ Note that $f$ can be written as function of $\beta$ alone without loss of generality since now

$$
f(\beta)=I / K=\beta u / v
$$

from which $u$ is determined as a function of $\beta$. The wage-rental ratio is also implicitly present, since with both $\beta$ and $u$ known, $\omega$ is determined by equation 18 .

${ }^{19}$ This says that the response of investment to the profit share is very large. If $\beta$ is 20 percent, moving from a profit share of 0.4 to 0.41 would have to give more than a 5 percent increase in the rate of growth of investment and from 0.4 to 0.5 by 50 percent.
} 


$$
\epsilon=\frac{\beta f^{\prime}(\beta)}{f(\beta)}>1
$$

where $\epsilon$ is the elasticity of $f$ with respect to the profit share.

Finally, we normalize equation (4) to the full employed labor force, $\bar{L}$, so that all variables are expressed on a per capita basis. This is often done in the standard model and makes for easy comparison. The SGM can now be expressed as a simultaneous system of differential equation: 20

$$
\begin{aligned}
& \frac{\dot{k}}{k}=f(\beta)-\delta-n \\
& \dot{\beta}=\theta\left[1-l \frac{k f(\beta)}{\beta}\right]
\end{aligned}
$$

where $n$ is the growth rate of the labor force ${ }^{21}$

The state variables of this system are the capital-labor ratio $k=K / \bar{L}$ and profit share $\beta$, while the jump variable is $I / K=f(\beta)$. Thus, at the beginning of each period, $k$ and $\beta$ are known from the previous period and generate new levels of investment and employment for the current period.

The long-run solution to the system of equations for model is obtained by setting the right-hand side of equations 22 equal to zero

$$
\begin{aligned}
f(\beta) & =\delta+n \\
k & =\frac{\beta}{l f(\beta)}
\end{aligned}
$$

where a functional form for $f$ must be assumed in order to get an explicit solution. Figure figure 9 shows a calibrated example, with $f(\beta)$ as described in the example below. In the model with a constant $\beta$, the system would come to rest somewhere along the $\dot{k}=0$ isocline in figure 9 . But with a variable $\beta$, if it turned out that there was less than full employment, the profit share would increase. This would in turn stimulate investment, which through the multiplier would raise income, and with a constant labor coefficient, employment. At the same time, investment raises the capital stock at some growth rate $\hat{K}$. If this latter rate exceeds $n$, the capital-labor ratio increases. The solution trajectory then departs the $\dot{k}=0$ isocline to the northeast.

Equilibrium occurs when the rate of growth of investment and capital are both equal to the exogenously given rate of growth of the labor force, $n$. At that point, the capital-labor ratio is constant and there is full employment of the labor force. As a result there is no tendency for income shares to change.

The Jacobian matrix of the right-hand side of the system of equations 222 is used to formally evaluate the local stability of the system around the steady state. Thus, the Jacobian is evaluated at full employment and full capacity utilization

$$
\mathrm{J}=\left[\begin{array}{cc}
f(\beta)-\delta-n & f^{\prime}(\beta) \\
-\theta \frac{l f(\beta)}{\beta} & -\theta l \frac{f(\beta)}{\beta^{2}}(\epsilon-1)
\end{array}\right]
$$

where the $J_{11}$ term of the Jacobian is zero in the steady state. Local stability depends on two conditions, first that the trace of the Jacobian is negative; that is, $J_{11}+J_{22}<0$. For this condition to hold, we must have $\epsilon>1$. The second condition is that the determinant $J_{11} J_{22}-J_{12} J_{21}=f^{\prime} / k>0$, which is automatically satisfied, so long as the economy is exhilarationist.

\footnotetext{
${ }^{20}$ The original model is embedded in this system of equations. Drop the second equation and hold $\beta$ constant, as it usually is, and the equilibrium condition reduces to the solution to equation $\sqrt{2}$ with $\gamma=\hat{K}$. If $\gamma$ is greater than $n$, unemployment must be falling. The second equation slows down the growth of investment, given that a rise in $I / k$ reduces $\beta$. The negative relationship between $\beta$ and $\gamma$ is then stabilizing.

${ }^{21}$ The first of these two equations is strikingly similar to the standard growth differential equation, expressed in per capita terms

$$
\hat{k}=s f(k)-n-\delta
$$

where the term $s f(k)$ simply describes how much of total output is saved on a per capita basis.
} 


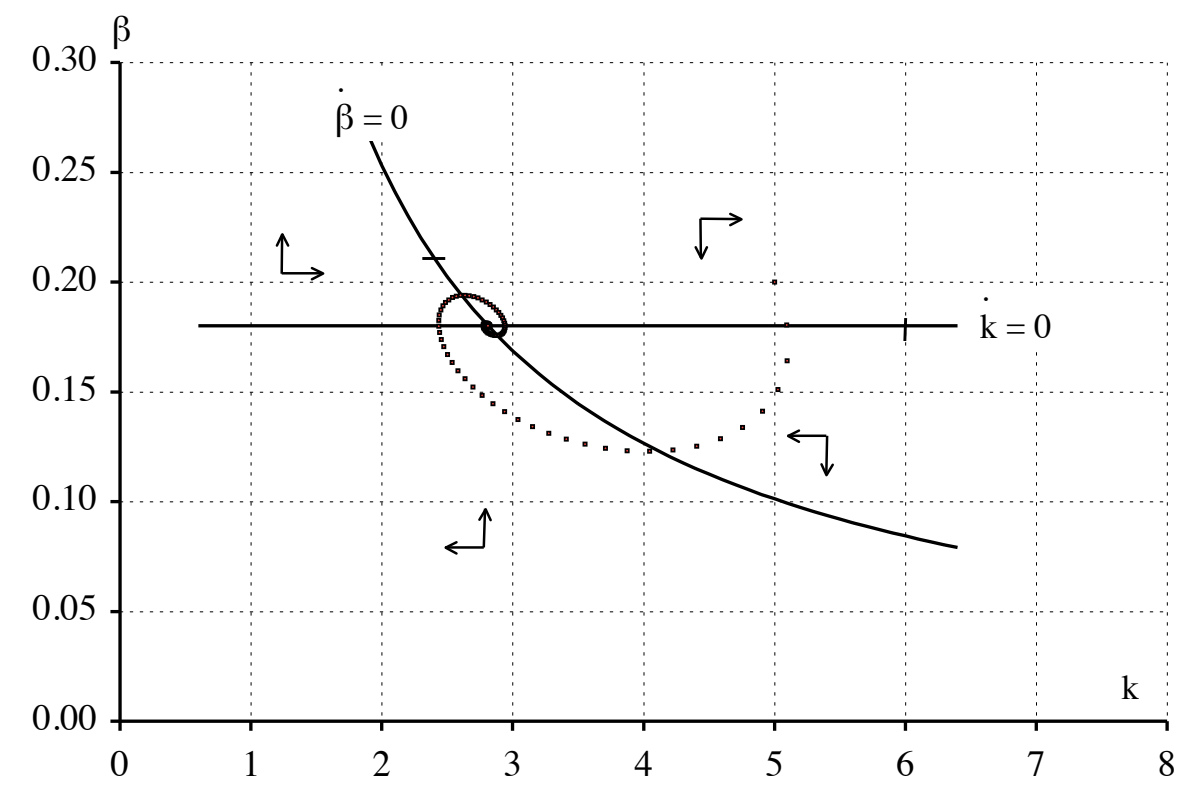

Figure 9: Adjustment in the SGM

Figure 10 shows the time paths for the rates of growth of investment and capital stock implied by the adjustment process shown in figure 9. The figure shows that the initial values of $k$ and $\beta$ are far from their steady-state values. While the trajectories exhibit significant variability initially, they eventually settle down and begin to come together by the 50th period. Employment and capacity utilization also converge as well, both to 100 percent.

There is a counterpart to this adjustment process in the standard model. Consider what happens there when the steady state is perturbed in figure 3 . The perturbation might take the form of the destruction of some part of the capital stock. The model then starts at $L_{0}, K_{0}$ and during the following period, capital expands to $K_{1}$, due to the investment during the year. In the diagram labor is held fixed and so capital obviously grows more rapidly than labor. The relative factor-price line must rotate in a clockwise fashion, increasing the wage-rental ratio. With a constant share of output devoted to capital accumulation, the rate of growth of capital declines until it again equals that of labor.

In the SGM example, the process is very closely related. All profit is invested, but profit itself is driven lower as wages rise with higher employment and capital stock growth slows as a result. Figure 9 shows that the system follows a stable focus with the both the profit share and capital-labor ratio first rising and then falling as the equilibrium is approached. What prevents monotonic adjustment to the new steady state? It is essentially that in the structuralist model, investment responds to profitability rather than output as a whole and is therefore more volatile. In figure 3 , investment drives the capital stock from $K_{0}$ to $K_{1}$, but the wage-rental rate increases so much that the next increment to the capital stock is less and may even fall. If labor growth is constant, employment fluctuates dramatically as shown in figure 9. Instead of a smooth increase in the capital-labor ratio, $k$ also increases rapidly and then falls back as the capital stock and labor growth rates come together. Of course the fall in $\beta$ would not affect profitability so dramatically, were the labor coefficient, $l$, and capital-output ratios not constant.

It is probably fair to say that this version of the SGM meets the standard model more than half way, in that it allows for full employment in the long run but with less than full capacity utilization in the short run. We might therefore want to refer to the model as a hybrid structuralist-standard model since like the 


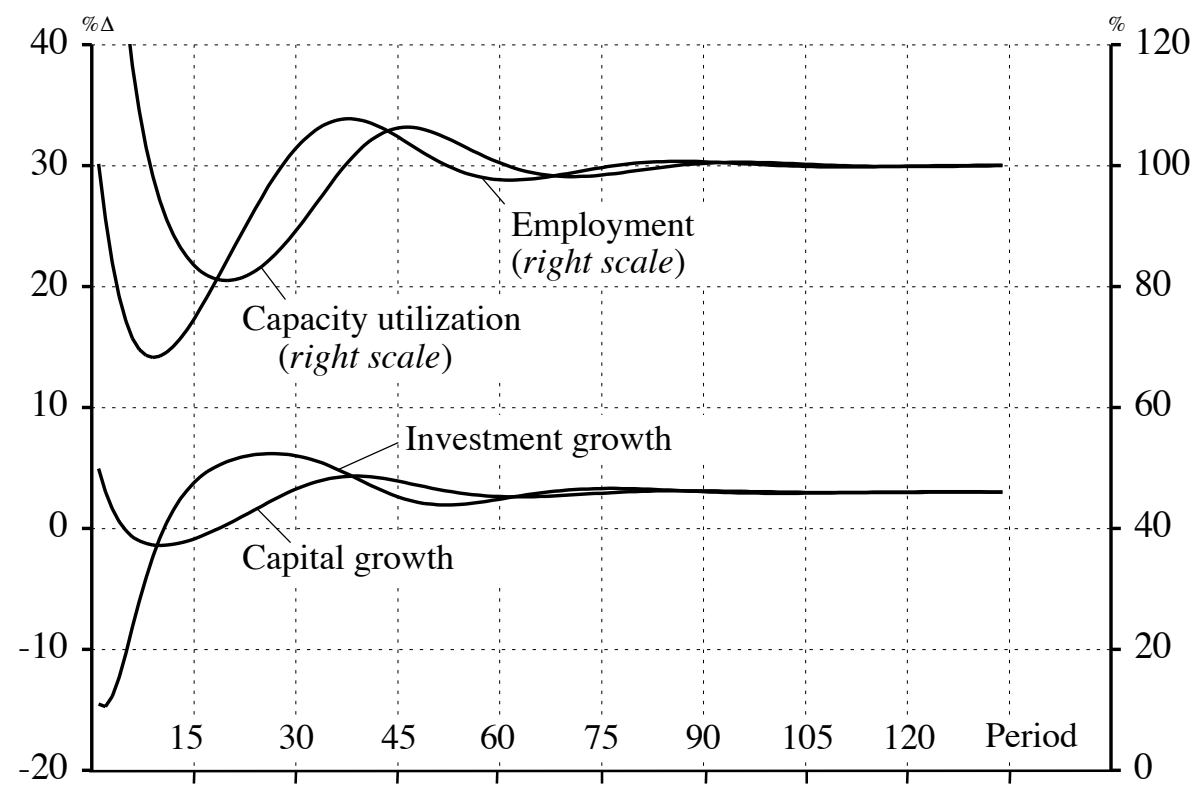

Figure 10: Adjustment in the structuralist model

standard model, it must ultimately adjust to an externally given rate of growth of the labor force. '

\subsection{Example}

Consider the SAM in table 3 and the additional information in table 4. How can a SGM be calibrated to this data that converges to full employment and capacity utilization? The first step is to specify a functional form for $f(\beta)$. There is very little guidance here from theory and indeed there is no guarantee that the function actually exists. But suppose that an econometric exercise were able to establish that the elasticity

Table 3: A Social Accounting Matrix

\begin{tabular}{|c|c|c|c|c|}
\hline Firms & Firms & $\begin{array}{l}\text { Households } \\
400\end{array}$ & $\begin{array}{l}\text { Invest } \\
100\end{array}$ & $\begin{array}{l}\text { Total } \\
500\end{array}$ \\
\hline $\begin{array}{l}\text { Households } \\
\text { wages } \\
\text { profits }\end{array}$ & $\begin{array}{l}400 \\
100\end{array}$ & & & 500 \\
\hline Savings & & 100 & & 100 \\
\hline Total & 500 & 500 & 100 & \\
\hline
\end{tabular}


Table 4: Additional Data for Calibration

Capacity utilization

Growth of the labor force

Adjustment parameter $\theta$

Employment ratio

Depreciation rate

$\begin{array}{cc}\text { Base SAM } & \text { Steady State } \\ 0.8 & 1 \\ 0.03 & 0.03 \\ 0.015 & 0.015 \\ 0.8 & 1 \\ 0.05 & 0.05\end{array}$

Source: Author's calculations.

of investment with respect to the profit share was equal to 2. A simple functional form might then be

$$
f(\beta)=z \beta^{2}
$$

where $z$ is a calibration constant. With full capacity utilization, the steady-state $f$ is constant and equal to $\delta+n=0.08$. We also know that

$$
\frac{\beta_{\infty}}{v}=0.08
$$

where $\beta_{\infty}$ is the steady-state value for $\beta$. Since equation 25 must also hold for this $\beta$, we can eliminate $\beta_{\infty}$ to find

$$
v^{2} z=\frac{1}{\delta+n} .
$$

The initial SAM must also be consistent with equation (25), however, and that requires that the capitaloutput ratio be set in the calibration process. It must be true that

$$
\frac{I_{0}}{K_{0}}=z \beta_{0}^{2}
$$

where the zero subscript indicates the value in the base SAM. With knowledge of the initial value of capacity utilization, we have

$$
z v=\frac{u_{0}}{\beta_{0}}
$$

where the initial profit share, $\beta_{0}$, can be read from the SAM, and is 0.2 . Solving these last two equations simultaneously, we find that $v=3.13$ and $z=1.28{ }^{22}$ From these two parameters, the rest of the model can be calibrated. The initial level of capital is $K=v Q=v Y_{0} / u_{0}$ or 1953.1 , where $Y_{0}$ and $u_{0}$ can be read from the data tables. The labor force is then $400 / 0.8=500$. So that the initial capital-labor ratio is $k=3.9$. Figures 11 and 12 shows the results. These figures plot two adjustment speeds, one for $\theta=0.15$, and a slower one with $\theta=0.015$. Note the significant impact on the trajectory that the adjustment speed has. In the fast case there is very little overshooting of capacity utilization or employment compared to figure 9 . even more in line with the standard model.

\subsection{Other stabilizing mechanisms}

The Taylor model is just one of many structuralist examples in which some additional mechanism is employed to reverse the instability introduced by the capacity utilization term. In an early model by Dutt, for example, monopoly power is used to set $\beta$ in a stabilizing fashion (Dutt, 1984). There the mark-up follows a concave path with respect to capacity utilization, rising first as industries are concentrated. The mark-up then falls as excess profits attract entry and foreign competition, or state imposed anti-trust mechanisms take effect.

\footnotetext{
${ }^{22}$ The solutions are $v=\frac{\beta_{0}}{u 0(\delta+n)}$ and $z=\frac{u_{0}}{v \beta_{0}}$.
} 


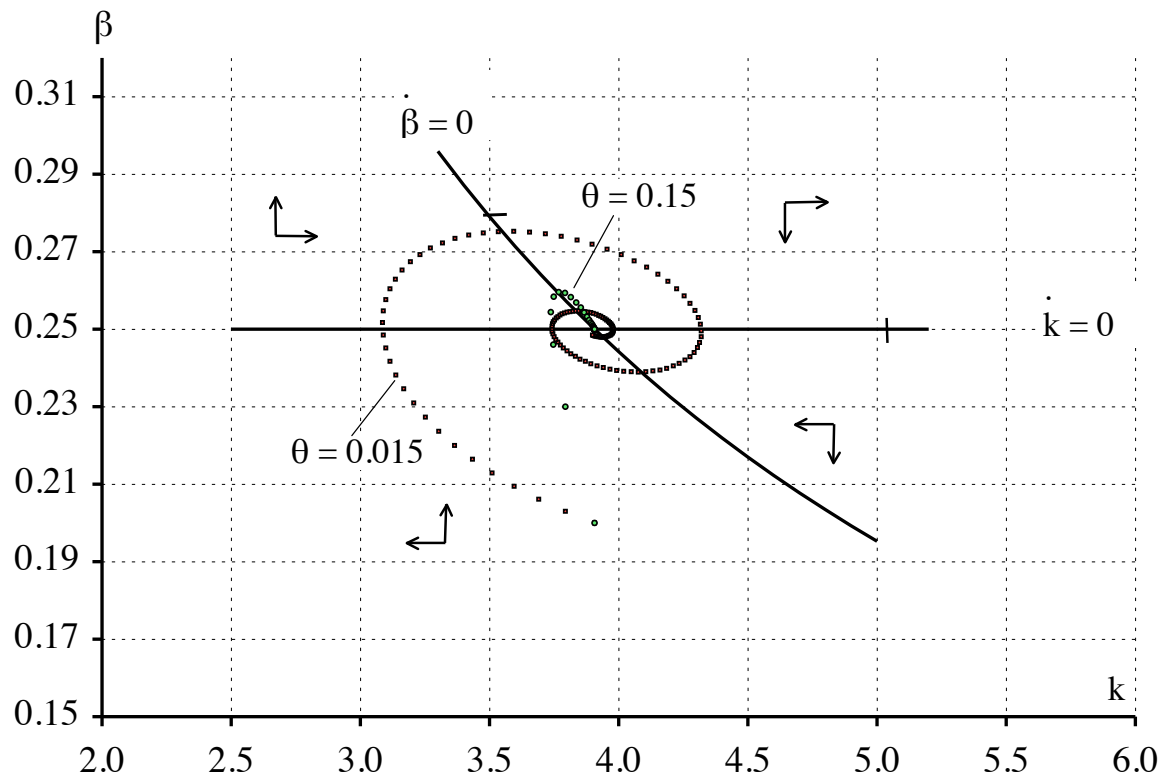

Figure 11: Different adjustment speeds

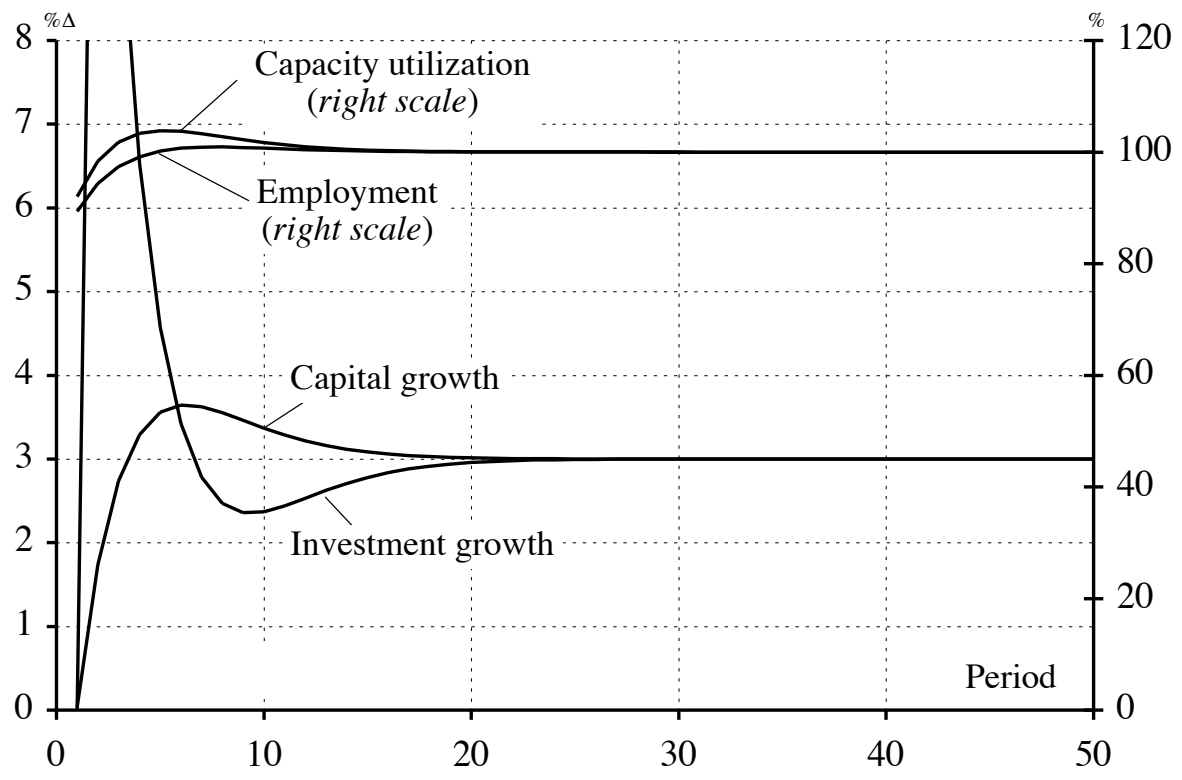

Figure 12: Fast adjustment of the profit share 
Similarly, Taylor offers a model in which inflation is introduced directly into the investment function in order to arrest the explosive effect of capacity utilization (Taylor, 1991). There, full capacity utilization causes inflation to accelerate and this effect overcomes that of rising $u$. Skott introduces the cost of finance, through a "financialization" effect to serve the same purpose. Setterfield and Lima have central bank policy, through the effect of inflation targeting, playing the role of rising wages in the canonical model of Taylor (1983).

Anytime an adjustment speed is introduced, the path of the model will depend on both the initial conditions and the adjustment parameter. In principle then, this adjustment parameter should be explained within the structural theory of the model, although it rarely is. Frequently, the stability properties of the model depend on the size of the adjustment parameter, in that it cannot be "too big." A stable adjustment process with an appropriately sized parameter is then just another way to impose a bound on the growth rate of investment ${ }^{23}$ One can calibrate the model to actual data to deduce its value. The path then depends on the initial SAM as well as how fast the adjusting variables dampen out.

\subsection{Path dependence, multiple equilibria and hysteresis}

Dutt argues that path dependency is an important characteristic of realistic models, since intuitively, "the destination depends on what happens along the way" (Dutt, 2005). While this assertion is hardly selfevident, Dutt marshals a number of convincing arguments that hysteresis, or irreversibility, is common in most real economies. Hysteresis, first applied to magnetism, implies remanence: a shock to an economy, followed by an equal and opposite shock, will not restore the model to its original equilibrium. This will be generally true in models for which the initial conditions play a role in the determination of the steady state of the model. Since shocks alter the effect of the original initial conditions, it follows that the model will not necessarily return to its original equilibrium of when the shock is reversed. Initial conditions are also important when there are multiple equilibria, since they can determine which of the equilibria are selected.

The standard model does not exhibit any of these characteristics since it converges to a unique globally stable equilibrium. More generally, the standard model is ergodic in that it "shakes free" from the influence of its past state, even when its parameters are stochastic (David, 2000). Ergodicity is usually considered an important characteristic of stochastic models, since it is then possible to reach any state of the model from any other state. Where one starts does not exclude any particular destination. Data collected from ergodic simulations is therefore free of any bias imposed on the model by its initial conditions. Ergodic models are free from bias in a more profound sense: nothing that the underlying agents do is affected by anything other than behavior of the agents themselves, either collectively or individually. Hysteresis can still be present, but there is nothing that guides the behavior of the model from above. The standard model is, of course, constrained from above by the rate of growth the labor force. A fully ergodic model would have the decision of whether to join the labor force, or indeed population growth itself, be determined from the ground up, that is, by the agents themselves.

Dutt notes that in order for structural history to matter, it is necessary for a model to have either multiple equilibria, a continuum of equilibria or exhibit hysteresis. The first and third rely on a detailed analysis of agent behavior, while the second, as we have seen, is a property of the pure structuralist approach, with investment growth linked to capacity utilization. (See figure 5). Dutt goes further to argue that hysteresis is very common, with the absence of hysteresis "a rarity." Hysteresis is grounded in individual agent decisionmaking, rather than imposed structure. Hysteresis derives from hysterons, model elements that switch on or off depending on local circumstances, neighborhood effects, time delays, biases arising from the availability heuristic and other forms of bounded rationality. Irreversibility due to loss aversion means that the direction of change influences the magnitude of change. These arguments are based on behavioral regularities rather

\footnotetext{
${ }^{23}$ Dutt shows that this can be done when introducing the expected rather than actual rate of profit into the $I / K$ function (Dutt, 2005). He lets

$$
\frac{d r^{e}}{d t}=\theta\left(r-r^{e}\right)
$$

be the adjustment of the expected profit rate, $r^{e}$ to the actual, $r$.
} 
than aggregate structural features. Apparently for structure to really matter, agency must be considered in very careful ways 24

Practical structuralist models are calibrated to an initial SAM and then adjustments are made to the behavioral parameters until the model tracks historical data reasonably well (Gibson and van Seventer, 2000, Lovinsky and Gibson, 2005, Taylor, 1990). Policy analysis can then be conducted around the calibrated path and recommendations tailored to the relevant structural constraints of the target economy can then be made. Indeed, this is why structuralist models are structuralist. A model with an investment function calibrated in this way is ipso facto "path dependent" in that were it adjusted to track a different set of data, it would have a different $\gamma$ and therefore converge to a different steady state. Whether the logistic equation is engineered to produce full capacity utilization in the steady state, as above, depends on the time frame for which the model is to be employed.

The discrete logistic $\gamma$ function is just one of many functional forms that might be used to describe the time path of investment. It has two fixed points, a trivial one at zero and one at $\gamma=(k-1) / k$, as seen above. The first is a repeller, that is unstable, while the second is an attractor, or stable equilibrium. Since there is only one attractor, the initial conditions do not matter; all roads lead to the same destination. Iterative models that have attracting fixed points, found by way of numerical simulations, allow calibrated parameters to determine the steady state. Small changes in policy variables do not send the model off on wholly different trajectories, and thankfully so ${ }^{25}$ Other plausible functions to describe investment growth may well have more than one attractor and thus the initial conditions would indeed matter. Depending on the initial SAM to which the model is calibrated, a difference equation simulation could converge to one of any number of equilibria. Examples include tangent and pitchfork bifurcations, in which fixed (or periodic points) appear for certain parameter values, come together and then disappear for others. Parameter changes can change a repelling fixed point into an attracting or neutral one, or vice versa.

"Lock-in" that derives from coordination failure has been discussed by Setterfield and others (Setterfield, 1997) ${ }^{26}$ Lock-in is a stronger property than remanence and hysteresis in that it refers to how equations of motion are themselves formulated. It is one thing to say that hysterons lead to non-ergodicity in models so that when the model arrives at some states, other states are not available (Durlauf, 1996). It is another to ignore forces that might build to break out of the locked-in equilibrium. Indeed, lock-in has been challenged by Liebowitz and Margolis, among others, on the grounds that if the "unavailable" states were Pareto superior, then presumably they could be found (Liebowitz and Margolis, 1994). Random experimentation in reinforcement learning models can bring this about (Sutton and Barto, 1998), as well as the standard compensation principle to allow trading to the new equilibrium even when some agents are locally worse off.

Good modeling is good modeling and so it is incumbent upon both structuralists and those attracted to the standard approach to think more deeply about the component parts of the model. Structuralists should strive to model precisely how the decisions of agents in the past have produced the structures that constrain agents of the present. These may be rational, or indeed, "predictably irrational" to borrow a fashionable term from behavioral economics, but they most assuredly must be predictable to some degree. The standard model clearly requires more attention to bounds on rationality and the speed with which markets adjust.

Finally, there is nothing to say that the SGM really needs to focus on the adjustment process to a steady-growth full employment, full capacity utilization equilibrium. The structuralist model, shorn of these

\footnotetext{
${ }^{24}$ Setterfield and others have raised the question of whether models that solve simultaneously for all variables can be path dependent in the same way, as say a random walk (Setterfield, 2001).

${ }^{25}$ Consider this:

The existence of sensitive dependence in dynamical systems has profound implications for scientists and mathematicians who use difference or differential equations as mathematical models. If a given system exhibits sensitive dependence on initial conditions, then numerical predictions about the fate of orbits are to be totally distrusted (emphasis added). For we can never know the exact seed or initial condition for our orbit or solution because we cannot make physical (or indeed social! BG) measurements with infinite precision. Even if we had exact measurements, we could never carry out the necessary computations. The small numerical errors that are always introduced in such numerical procedures throw us off our original orbit and onto another whose ultimate behavior may be radically different (Blanchard et al. 2002).
}

${ }^{26}$ See Setterfield 2001) and references cited therein. 
moorings, is a fine model with which to simulate an economy. Fine, so long as one is confident in the forecast for investment path as well as the structural rigidity of the productive structure. Above all, labor can have no meaningful role in determining output and the rate of unemployment can increase or decrease with no direct feedback on the capital-output ratio. These are all significant assumptions, of course, and probably explain why the structuralist model is often referred to as a medium-run model, that is, not really designed to capture the "long run", in which the economy is fully adjusted to factor availability.

\section{Conclusions}

What then is the essential ingredient that makes a model structuralist? It has been argued here that both the standard and structuralist models rely on an exogenous independent variable. In the case of the standard model, it is the growth of the labor force. For the structuralist model, it is rather the animal spirits component in the growth of investment. In the case of the latter model, part of the structure is the investment climate, but it is not amenable to full theoretical treatment. It is inherently subjective, historical or otherwise locally determined and not subject to treatment within the standard optimization framework.

The capital stock will only achieve steady growth when investment and the capital stock are growing at the same rate, and this is true for models of either stripe. Steady growth of the capital stock, at whatever rate, therefore necessarily implies steady growth of investment. All the feedback that arises from the short-run equilibrium between savings and investment must therefore dampen out when the model reaches the steady state. One of the major hurdles of the structuralist framework is getting the effect of capacity utilization on the growth path of investment to dampen out as the model reaches full capacity utilization. Here the shortage of capacity is at its greatest and one would expect that investment would surge. In fact, other forces must always come into play to keep investment in check.

The irony of the structuralist model is that these forces are themselves rooted in short-run reactions of variables with significant degrees of freedom, i.e., variables that cannot be determined structurally. Agency must intervene and structuralists have conceded to this point to various degrees and in a multiplicity of ways. Other contributions to this volume show this can be done in interesting and creative ways, but it has been the purpose of this paper to show more precisely how and why a comprehensive theory of individual agents making investment decisions is necessary.

\section{References}

Aghion, P. and P. Howitt (1998). Endogenous Growth Theory. Cambridge, MA: MIT Press.

Barrow, R. and X. Sala-i-Martin (2004). Economic Growth. New York: McGraw Hill.

Bhaduri, A. and S. Marglin (1990). Unemployment and the real wage: The economic basis for contesting political ideologies. Cambridge Journal of Economics 14(4), 375-93.

Blanchard, P., R. L. Devaney, and G. R. Hall (2002). Differential Equations (2 ed.). Pacific Grove, CA: Brooks-Cole.

David, P. A. (2000). Path dependence, its critics and the quest for 'historical economics'. In P. Garrouste and S. Ioannides (Eds.), Evolution and Path Dependence in Economic Ideas: Past and Present. Cheltenham, UK: Edward. Elgar.

Domar, E. D. (1946). Capital expansion, rate of growth and employment. Econometrica 14, $137-47$.

Durlauf, S. N. (1996). A theory of persistent income inequality. Journal of Economic Growth 1(1), 75-93.

Dutt, A. K. (1984). Stagnation, income distribution and monopoly power. Cambridge Journal of Economics 8, 25-40. 
Dutt, A. K. (1997). Equilibrium, path dependence and hysteresis in post-Keynesian models. In P. Arestis, G. Palma, and M. Sawyer (Eds.), Capital Controversy, Post-Keynesian Economics and the History of Economic Thought: Essays in Honour of Geoff Harcourt. London: Routledge.

Dutt, A. K. (2005). Robinson, history and equilibrium. In B. Gibson (Ed.), Joan Robinson's Economics: A Centennial Celebration. Cheltenham, UK: Edward Elgar.

Dutt, A. K. (2008). Education, growth and distribution: a heterodox macrodynamic perspective. Department of Economics, University of Notre Dame.

Gibson, B. (2003a). An essay on late structuralism. In A. Dutt and J. Ros (Eds.), Development Economics and Structuralist Macroeconomics: Essays in Honor of Lance Taylor, Chapter 2, pp. 52-76. Cheltenham, UK: Edward Elgar.

Gibson, B. (2003b). Thinking outside the Walrasian box. International Journal of Political Economy 33(2), $36-46$.

Gibson, B. (2005). The transition to a globalized economy: Poverty, human capital and the informal sector in a structuralist CGE model. Journal of Development Economics 78(1), 60-94.

Gibson, B. (2007). A multi-agent systems approach to microeconomic foundations of macro. University of Massachusetts, Department of Economics Working Paper Series.

Gibson, B. and D. E. van Seventer (2000). A tale of two models: Comparing structuralist and neoclassical computable general equilibrium models for South Africa. International Review of Applied Economics 14 (2), 149-71.

Harrod, R. (1937). An essay in dynamic theory. Economic Journal 49, 14-33.

Kalecki, M. (1971). Selected Essays on the Dynamics of the Capitalist Economy. Cambridge, UK: Cambridge Univerisity Press.

Keynes, J. M. (1936). The General Theory of Employment, Interest and Money. London: Macmillan.

Lavoie, M. (1992). Foundation of Post-Keynesian Economic Analysis. Cheltenham, UK: Edward Elgar.

Lavoie, M., G. Rodríguez, and M. Seccareccia (2004). Similitudes and discrepancies in post-Keynesian and Marxist theories of investment: A theoretical and empirical investigation. International Review of Applied Economics 18(2), 127-149.

Liebowitz, S. J. and S. E. Margolis (1994). Network externality: an uncommon tragedy. Journal of Economic Perspectives 8(2), 133-150.

Lima, G. T. and M. Setterfield (2008). Inflation targeting and macroeconomic stability in a post Keynesian economy. Journal of Post Keynesian Economics 30(3), 435-461.

Lovinsky, J. and B. Gibson (2005). A Robinson model for Argentina. In B. Gibson (Ed.), Joan Robinson's Economics: A Centennial Celebration, Chapter 11, pp. 225-44. Cheltenham, UK: Edward Elgar.

Mohun, S. (2008). Aggregate capital productivity in the U.S. economy. Queen Mary, University of London.

Pasinetti, L. L. (1962). Rate of profit and income distribution in relation to the rate of economic growth. Review of Economic Studies 29, 267-79.

Robinson, J. (1956). The Accumulation of Capital. London: Macmillan.

Ros, J. (2003). Stabilization, adjustment and growth. In A. K. Dutt and J. Ros (Eds.), Development Economics and Structuralist Macroeconomics: Essays in Honor of Lance Taylor. Cheltenham, U. K.: Edward Elgar. 
Setterfield, M. (1997). 'History versus equilibrium' and the theory of economic growth. Cambridge Journal of Economics 21, 365-78.

Setterfield, M. (2001). Cumulative causation, interrelatedness and the theory of economic growth: A reply to Argyrous and Toner. Cambridge Journal of Economics 25(1), 107-112.

Setterfield, M. and A. Budd (2008). A Keynes-Kalecki model of cyclical growth with agent-based features. Department of Economics, Trinity College.

Skott, P. (1989). Conflict and effective demand in economic growth. Cambridge, UK: Cambridge Univerisity Press.

Skott, P. (2008). Investment functions, stability and the reserve army of labor. University of Massachusetts Working Paper Series.

Solow, R. M. (1956). A contribution to the theory of economic growth. Quarterly Journal of Economic 70(1), $65-94$.

Sutton, R. S. and A. G. Barto (1998). Reinforcement Learning. Cambridge, MA and London: MIT Press.

Taylor, L. (1983). Structuralist Macroeconomics. Boston, MA: Basic Books.

Taylor, L. (Ed.) (1990). Socially Relevant Policy Analysis. Cambridge, MA: Massachusetts Institute of Technology.

Taylor, L. (1991). Income Distribution, Inflation, and Growth. Cambridge, MA: MIT Press.

Zamparelli, L. (2008). Direction and intensity of technical change: a micro model. New School for Social Research. 